\title{
Sugar Vinyl Sulfoxide Glycoconjugation of Peptides and Lysozyme: Abrogation of Proteolysis at the Lysine Sites
}

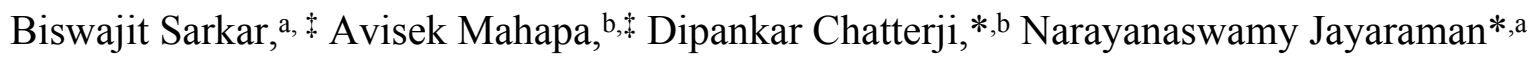

${ }^{a}$ Department of Organic Chemistry, ${ }^{b}$ Molecular Biophysics Unit, Indian Institute of Science, Bangalore 560 012, India

\section{Table of Contents}

$\begin{array}{ll}\text { 1. General Information } & \text { S2 }\end{array}$

2. Experimental Procedures $\quad$ S2

3. Mass, ${ }^{1} \mathrm{H}$ and ${ }^{13} \mathrm{C}$ NMR Spectra $\quad \mathrm{S} 7$

4. Protein Mass Spectrometry $\quad$ S15

5. Methods and Solvents for LCMS S15

6. Modification of Lysozyme $\quad$ S16

7. In-Gel Tryptic Digestion Protocol S17

8. LCMS Spectrum and Data of Native Lysozymer S18

9. LCMS Spectrum and Data of Modified Lysozyme S19

10. LCMS Spectrum and Data of Native Lysozyme after Trypsin Digestion S20

11. LCMS Spectrum and Data of Modified Lysozyme after Trypsin Digestion $\quad$ S24

12. Tryptic Digestion Pattern of Native and Modified Lysozyme S28

$\begin{array}{lr}\text { 13. Assay of Lysozyme Lytic Activity } & \text { S29 }\end{array}$

$\begin{array}{lr}\text { 14. Reference } & \text { S29 }\end{array}$ 


\section{General Information}

Solvents were dried and distilled according to literature procedures. All the chemicals and lysozyme protein were purchased from commercial sources and used without further purification. Silica gel (100-200 mesh) was used for column chromatography and thin layer chromatography (TLC) analysis was performed on commercial plates coated with silica gel 60 F254. Visualization of the spots on the TLC plates was achieved by UV radiation or spraying $5 \%$ sulfuric acid in ethanol or ninhydrin in ethanol solution. Mass spectral characterizations were performed on ESI-QTOF (Waters Xevo ${ }^{\circledR}$ G2-XS QTOF), operating in the positive ion mode, on samples in either $\mathrm{MeCN} /$ water or $\mathrm{MeOH} /$ water solution. ${ }^{1} \mathrm{H}$ and ${ }^{13} \mathrm{C} \mathrm{NMR}$ spectral analyses were performed on a spectrometer operating at 400 and $100 \mathrm{MHz}$, respectively. Processing of the FID data was performed on Bruker TopSpin ${ }^{\mathrm{TM}}$ and Mnova softwares, with default settings. Chemical shifts are reported with respect to tetramethylsilane for ${ }^{1} \mathrm{H}$ NMR and the central line $(77.0 \mathrm{ppm})$ of $\mathrm{CDCl}_{3}$ for ${ }^{13} \mathrm{C}$ NMR spectra. Coupling constants $(J)$ are reported in Hertz. Standard abbreviations s, d, t, dd, br s, m, and app refer to singlet, doublet, triplet, doublet of doublet, broad singlet, multiplet, and apparent, respectively.

\section{Experimental Procedures}

5: A mixture of benzyl 4,6-di-O-acetyl-2,3-dideoxy-3-(p-tolylsulfinyl)- $\alpha$-D-erythro-hex-3enopyranoside (1) $(0.10 \mathrm{~g}, 0.22 \mathrm{mmol})$ and ethanolamine $(8 \mu \mathrm{L}, 0.13 \mathrm{mmol})$ was dissolved in aq. $\mathrm{MeOH}(40 \% \mathrm{v} / \mathrm{v})(10 \mathrm{~mL})$, stirred at $40{ }^{\circ} \mathrm{C}$ for $12 \mathrm{~h}$, solvents evaporated in vacuo and purified $\left(\mathrm{SiO}_{2}\right)\left(\right.$ EtOAc) to afford $5(0.035 \mathrm{~g}, 64 \%)$, as a foamy solid. $R_{\mathrm{f}}=0.25($ EtOAc $) ;{ }^{1} \mathrm{H}$ NMR $(400$ $\mathrm{MHz}, \mathrm{CDCl}_{3}$ ): $\delta 7.52(\mathrm{~d}, J=7.6 \mathrm{~Hz}, 2 \mathrm{H}$, aromatic), 7.31-7.21 (band, $7 \mathrm{H}$, aromatic), 6.59 (app. 
s, $1 \mathrm{H}, \mathrm{H}-4), 5.03(\mathrm{~d}, J=3.8 \mathrm{~Hz}, 1 \mathrm{H}, \mathrm{H}-1), 4.76\left(\mathrm{~d}, J=12 \mathrm{~Hz}, 1 \mathrm{H}, \mathrm{PhCH}_{2 \mathrm{a}}\right), 4.52(\mathrm{~d}, J=12 \mathrm{~Hz}$, $\left.1 \mathrm{H}, \mathrm{PhCH}_{2}\right), 4.45(\mathrm{~d}, J=3.8 \mathrm{~Hz}, 1 \mathrm{H}, \mathrm{H}-2), 3.81$ (dd, $\left.J=3.2 \mathrm{~Hz}, 11.6 \mathrm{~Hz}, 1 \mathrm{H}, \mathrm{H}-6 \mathrm{a}\right), 3.68$ (dd, $J$ $=2.8 \mathrm{~Hz}, 11.6 \mathrm{~Hz}, 1 \mathrm{H}, \mathrm{H}-6_{\mathrm{b}}$ ), 3.31 (t, $J=4.8 \mathrm{~Hz}, 2 \mathrm{H}, \mathrm{CH} 2 \mathrm{OH}$ ), 2.93 (app.d, $J=2.8 \mathrm{~Hz}, 1 \mathrm{H}, \mathrm{H}-$ 5), 2.46-2.41 (band, $\left.1 \mathrm{H}, \mathrm{CH}_{2 \mathrm{a}} \mathrm{NH}\right), 2.31(\mathrm{~s}, 3 \mathrm{H}), 2.08-2.017\left(\mathrm{~m}, 1 \mathrm{H}, \mathrm{CH}_{2 \mathrm{~b}} \mathrm{NH}\right) ;{ }^{13} \mathrm{C} \mathrm{NMR}$ $\left(\mathrm{CDCl}_{3}, 100 \mathrm{MHz}\right) \delta 143.2,142.3,139.2,137.0,130.1,128.6,128.6,128.2,128.2$ (aromatic), 126.8 (C-4), 126.7 (aromatic), $94.1(C-1), 71.0\left(\mathrm{PhCH}_{2}\right), 69.9(C-5), 64.5(C-6), 61.6(C-2), 54.5$ $\left(\mathrm{CH}_{2} \mathrm{OH}\right), 48.4\left(\mathrm{CH}_{2} \mathrm{NH}\right), 21.5\left(\mathrm{CH}_{3}\right)$; ESI-MS m/z: $[\mathrm{M}+\mathrm{Na}]^{+}$calcd. For $\mathrm{C}_{22} \mathrm{H}_{27} \mathrm{NO}_{5} \mathrm{SNa}$, 440.1508; found: 440.1507 .

7: A mixture of benzyl 4,6-di-O-acetyl-2,3-dideoxy-3-(p-tolylsulfinyl)- $\alpha$-D-erythro-hex-3enopyranoside (1) (103 mg, $0.23 \mathrm{mmol}$ ), serine methyl ester hydrochloride (6) (24 mg, 0.15 $\mathrm{mmol})$ and $\mathrm{NaHCO}_{3}(5 \mathrm{mg})$ was dissolved in aq. $\mathrm{MeOH}(40 \% \mathrm{v} / \mathrm{v})(5 \mathrm{~mL}, \mathrm{pH} 7.5-8)$ and stirred at $40{ }^{\circ} \mathrm{C}$ for $16 \mathrm{~h}$, solvents evaporated in vacuo and purified $\left(\mathrm{SiO}_{2}\right)$ (pet. ether/EtOAc, followed by $\mathrm{CHCl}_{3} / \mathrm{MeOH}$ ) to afford 7 (58 $\mathrm{mg}, 74 \%$ ), as a diastereomeric mixture (ratio 5:1). $R_{\mathrm{f}}=0.2$ (EtOAc); ${ }^{1} \mathrm{H}$ NMR (400 MHz, $\left.\mathrm{CDCl}_{3}\right): \delta 7.53(\mathrm{~d}, J=7.6 \mathrm{~Hz}, 2.7 \mathrm{H}), 7.32-7.26(\mathrm{~m}, 8.9 \mathrm{H}), 5.60$ (s, $1 \mathrm{H}), 5.30(\mathrm{~s}, 0.36 \mathrm{H}), 5.09$ (d, $J=2.8 \mathrm{~Hz}, 1.02 \mathrm{H}), 5.04(\mathrm{~s}, 0.3 \mathrm{H}), 4.77(\mathrm{~d}, J=11.6 \mathrm{~Hz}, 1.4 \mathrm{H})$, $4.60(\mathrm{~d}, J=12 \mathrm{~Hz}, 1.3 \mathrm{H}), 4.43(\mathrm{~s}, 1.1 \mathrm{H}), 4.16(\mathrm{~s}, 0.5 \mathrm{H}), 4.10(\mathrm{~d}, J=3.6 \mathrm{~Hz}, 2.2 \mathrm{H}), 3.89-3.82$ (m, 2.8 H), 3.71 (s, 3.2 H), 3.67-3.65 (m, 2.6 H), 3.37 (app. s, 1.1 H), 2.43 (s, $4.2 \mathrm{H}), 2.06$ (s, 1.7 H), 1.25 (s, $0.8 \mathrm{H}) ;{ }^{13} \mathrm{C}$ NMR (100 MHz, $\left.\mathrm{CDCl}_{3}\right): \delta 170.5,170.1,169.5,169.4,145.1,144.8$, $141.7,137.5,137.0,136.8,136.6,135.4,130.0,129.8,128.6,128.3,128.2,128.1,127.8,92.8$, 91.4, 70.8, 70.3, 68.3, 62.4, 61.2, 60.6, 21.6, 20.7, 20.6, 20.5; ESI-MS $m / z:[\mathrm{M}+\mathrm{Na}]^{+}$calcd. For $\mathrm{C}_{26} \mathrm{H}_{31} \mathrm{NO}_{8} \mathrm{SNa}$, 540.1668; found: 540.1666 . 
9: A mixture of benzyl 4,6-di- $O$-acetyl-2,3-dideoxy-3-( $p$-tolylsulfinyl)- $\alpha$-D-erythro-hex-3enopyranoside (1) $(89 \mathrm{mg}, 0.20 \mathrm{mmol})$, lysine hydrochloride (8) $(23.8 \mathrm{mg}, 0.13 \mathrm{mmol})$ and $\mathrm{NaHCO}_{3}(5 \mathrm{mg})$ was dissolved in aq. $\mathrm{MeOH}(40 \%)(5 \mathrm{~mL}, \mathrm{pH} 7.5-8)$ and stirred at $40{ }^{\circ} \mathrm{C}$ for 16 h. solvents were evaporated in vacuo and purified $\left(\mathrm{SiO}_{2}\right)$ (pet ether/EtOAc) to afford $9(55 \mathrm{mg}$, $81 \%)$, as a diastereomeric mixture (ratio $=1: 0.35) . \quad R_{\mathrm{f}}=0.18\left(\right.$ EtOAc). ${ }^{1} \mathrm{H}$ NMR $(400 \mathrm{MHz}$, $\mathrm{CDCl}_{3}$ ): $\delta 7.96$ (br s, $\left.1.3 \mathrm{H}\right), 7.67(\mathrm{~d}, J=6.8 \mathrm{~Hz}, 1.5 \mathrm{H}), 7.55-7.53(\mathrm{~m}, 0.5 \mathrm{H}), 7.49$ (d, $J=7.6 \mathrm{~Hz}$, 2.1 H), 7.35-7.29 (m, 1.6 H), 7.19-7.11 (m, $8.4 \mathrm{H}), 7.00$ (d, $J=7.2 \mathrm{~Hz}, 1.8 \mathrm{H}), 6.74$ (br s, $1.0 \mathrm{H})$, $6.60(\mathrm{~s}, 0.2 \mathrm{H}), 4.81(\operatorname{app~s}, 1.4 \mathrm{H}), 4.71-4.63(\mathrm{~m}, 2.5 \mathrm{H}), 4.56(\mathrm{~d}, J=12 \mathrm{~Hz}, 0.5 \mathrm{H}), 4.49$ (d, $J=$ $12 \mathrm{~Hz}, 1.3 \mathrm{H}), 4.24$ (t, J=4.4 Hz, 0.7 H), 4.12 (app s, $2.7 \mathrm{H}), 3.84$ (br s, $1.8 \mathrm{H}), 3.65$ (s, 0.6 H), 3.47 (s, 0.9 H), 3.09 (s, 1.6 H), 2.40-2.33 (m, 1.5 H), 2.27 (s, 3 H), 2.20 (s, 2.1 H), 2.08-2.03 (m, $1.0 \mathrm{H}), 1.88(\operatorname{app~s}, 3.7 \mathrm{H}), 1.46(\mathrm{br} \mathrm{s}, 4.0 \mathrm{H}), 1.25(\mathrm{~s}, 1.0 \mathrm{H}) ;{ }^{13} \mathrm{C} \mathrm{NMR}\left(100 \mathrm{MHz}, \mathrm{CDCl}_{3}\right): \delta$ $174.45,174.23,170.36,170.29,142.72,141.49,140.42,138.97,136.41,136.39,130.18,128.91$, $128.49,128.20,126.46,126.00,93.66,93.37,70.11,68.36,66.63,65.21,57.71,54.63,48.78$, $46.85,46.72,35.18,30.37,30.18,29.68,22.60,22.56,21.43,21.24,20.67$. ESI-MS m/z: $[\mathrm{M}+\mathrm{H}]^{+}$calcd. For $\mathrm{C}_{28} \mathrm{H}_{37} \mathrm{~N}_{2} \mathrm{O}_{7} \mathrm{~S}, 545.2327$; found 545.2327.

11: A mixture of benzyl 4,6-di-O-acetyl-2,3-dideoxy-3-( $p$-tolylsulfinyl)- $\alpha$-D-erythro-hex-3enopyranoside (1) (0.124 g, $0.27 \mathrm{mmol})$, arginine (10) $(31.4 \mathrm{mg}, 0.18 \mathrm{mmol})$ and $\mathrm{NaHCO}_{3}(3$ $\mathrm{mg})$ was dissolved in aq. $\mathrm{MeOH}(2: 1)(5 \mathrm{~mL}, \mathrm{pH} 7.5-8)$ and heated at $40{ }^{\circ} \mathrm{C}$ for $16 \mathrm{~h}$, solvents were evaporated in vacuo and purified $\left(\mathrm{SiO}_{2}\right)\left(\mathrm{MeOH} / \mathrm{CHCl}_{3}\right.$, linear gradient) to afford 11 (70 mg, $70 \%$ ), as a diastereomeric mixture (ratio 9:1). $R_{\mathrm{f}}=0.6\left(20 \% \mathrm{MeOH} / \mathrm{CHCl}_{3}\right) ;{ }^{1} \mathrm{H} \mathrm{NMR}(400$ $\mathrm{MHz}, \mathrm{CDCl}_{3}$ ): 7.64-7.50 (m, 5.1 H), 7.36-7.32 (m, 4.1 H), 7.01-6.9 (br., $\left.4 \mathrm{H}\right), 6.6$ (app. s, $1.2 \mathrm{H}$ ), 5.04 (app. s, 1 H), 4.86-4.76 (m, 0.4 H), 4.69-4.42 (m, 3.2 H), 4.25-4.17 (m, 3 H), 3.04 (br s, 3.6 
H), 2.73 (br s, 1.3 H), 2.41-2.31 (m, 4.4 H), 2.06-2.01 (m, $4.3 \mathrm{H}), 1.40-1.36(\mathrm{~m}, 2.7 \mathrm{H}), 1.28(\mathrm{~s}$, $1.9 \mathrm{H}) ;{ }^{13} \mathrm{C} \mathrm{NMR}\left(100 \mathrm{MHz}, \mathrm{CDCl}_{3}\right): \delta 178.22,170.62,157.28,157.22,143.09,142.43,140.84$, $137.91,137.10,136.49,130.18,128.64,128.45,128.17,127.87,127.78,127.64,127.28,126.97$, 95.21, 95.09, 70.68, 68.57, 65.34, 65.10, 65.01, 54.06, 41.16, 29.63, 24.68, 21.52, 21.46, 20.86. ESI-MS m/z: $[\mathrm{M}+\mathrm{H}]^{+}$calcd. for $\mathrm{C}_{28} \mathrm{H}_{37} \mathrm{~N}_{4} \mathrm{O}_{7} \mathrm{~S}, 573.2383$; found 573.2393.

14: A mixture of benzyl 4,6-di-O-acetyl-2,3-dideoxy-3-(p-tolylsulfinyl)- $\alpha$-D-erythro-hex-3enopyranoside (1) (0.21 g, $0.45 \mathrm{mmol})$, Boc-Lys-Lys-OMe (12) $(58 \mathrm{mg}, 0.15 \mathrm{mmol})$ and $\mathrm{NaHCO}_{3}(2 \mathrm{mg})$ was dissolved in aq. $\mathrm{MeOH}(40 \%)(10 \mathrm{~mL}, \mathrm{pH} 7.5-8)$ and stirred at $40{ }^{\circ} \mathrm{C}$ for 16 h, solvents evaporated in vacuo and purified $\left(\mathrm{SiO}_{2}\right)\left(\mathrm{CHCl}_{3} / \mathrm{MeOH}\right)$ to afford $14(0.12 \mathrm{~g}, 72 \%)$, as a diastereomeric mixture (ratio $=1: 0.46) . \underline{R}_{\mathrm{f}}=0.6\left(20 \% \mathrm{MeOH} / \mathrm{CHCl}_{3}\right) ;{ }^{1} \mathrm{H}$ NMR $(400 \mathrm{MHz}$, $\left.\mathrm{CDCl}_{3}\right)$ : 7.58-7.50 (m, 6.4 H), 7.38-7.27 (m, 17.8 H), 7.24 (s, 1.6 H), 7.09-6.99 (m, 1.2 H), 6.78$6.76(\mathrm{~m}, 0.6 \mathrm{H}), 6.59$ (br s, $1.4 \mathrm{H}), 6.16(\mathrm{br} \mathrm{s}, 0.5 \mathrm{H}), 5.37-5.36$ (m, 0.5 H), 5.05-4.94 (m, 2.8 H), 5.05-4.94 (m, 1.2 H), 4.85-4.79 (m, 4.3 H), 4.70-4.56 (m, 3.5 H), 4.54-4.51 (br. m, 3.9 H), 4.144.08 (m, 1.3 H), 3.80 (app. s, 4.9 H), 3.73-3.71 (m, 6.9 H), 3.52 (app d, $J=2.4$ Hz, 0.6 H), 3.233.14 (m, 4.0 H), 2.87 (br s, 1.5 H), 2.37 (app s, 10.3 H), 2.01-1.97 (m, 2.5 H), 1.85-1.71 (m, 12.0 H), 1.50 (br s, $3.7 \mathrm{H}), 1.44$ (s, $9 \mathrm{H}), 1.27-1.23(\mathrm{~m}, 9.8 \mathrm{H}) ;{ }^{13} \mathrm{C}$ NMR $\left(100 \mathrm{MHz}, \mathrm{CDCl}_{3}\right): \delta 172.5$, $171.0,155.3,151.3,143.8,142.1,139.1,136.7,130.6,130.1,130.0,128.5,128.4,128.2,128.0$ $127.8,126.8,126.7,126.4,126.0,95.4,94.8,93.9,79.7,77.32,70.9,70.4,69.9,64.5,64.2,60.1$, 54.3, 54.0, 52.2, 46.5, 42.0, 32.8, 32.8, 32.1, 31.3, 28.8, 28.3, 27.9, 22.7, 21.5, 21.4. ESI-MS $\mathrm{m} / \mathrm{z}$ : $[\mathrm{M}+\mathrm{H}]^{+}$calcd. for $\mathrm{C}_{58} \mathrm{H}_{77} \mathrm{~N}_{4} \mathrm{O}_{13} \mathrm{~S}_{2}, 1101.4929$; found 1101.4978. 
15: A mixture of benzyl 4,6-di-O-acetyl-2,3-dideoxy-3-( $p$-tolylsulfinyl)- $\alpha$-D-erythro-hex-3enopyranoside (1) (38.5 mg, $0.084 \mathrm{mmol}$ ), Boc-Lys-Ala-Lys-OMe (13) (13 mg, $0.028 \mathrm{mmol})$ and $\mathrm{NaHCO}_{3}(2 \mathrm{mg})$ was dissolved in aq. $\mathrm{MeOH}(40 \%)(5 \mathrm{~mL}, \mathrm{pH} 7.5-8)$ and stirred at $40{ }^{\circ} \mathrm{C}$ for $16 \mathrm{~h}$, solvents evaporated in vacuo and re-suspended in EtOAc/MeOH (1:1). Characterization was carried out using LCMS technique and the product was eluting at between 10.7 and 11.1 min. under method A (vide infra). 


\section{Mass, ${ }^{1} \mathrm{H}$ and ${ }^{13} \mathrm{C}$ NMR Spectra}

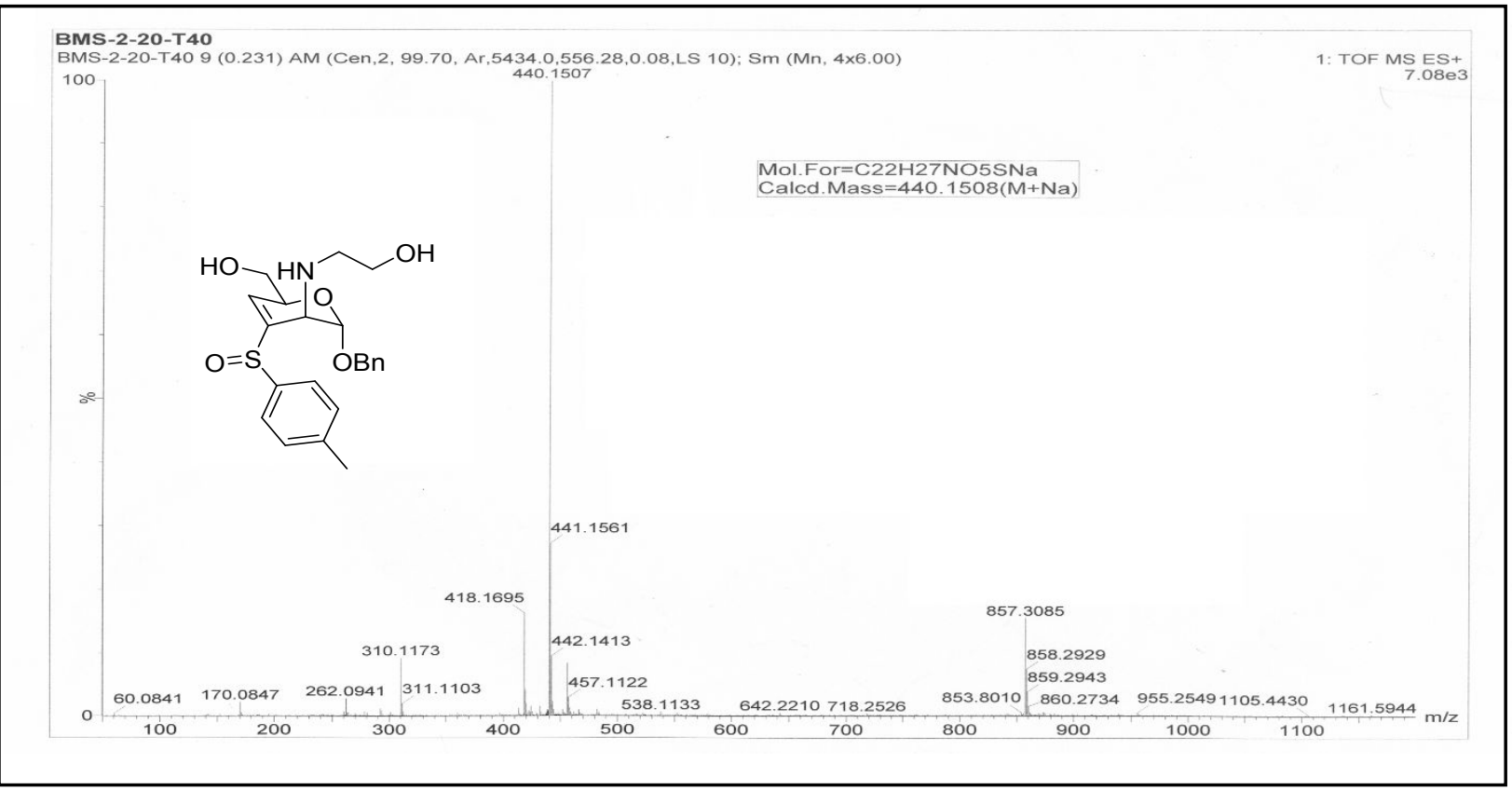

Figure S1. ESI-MS spectrum of 5.

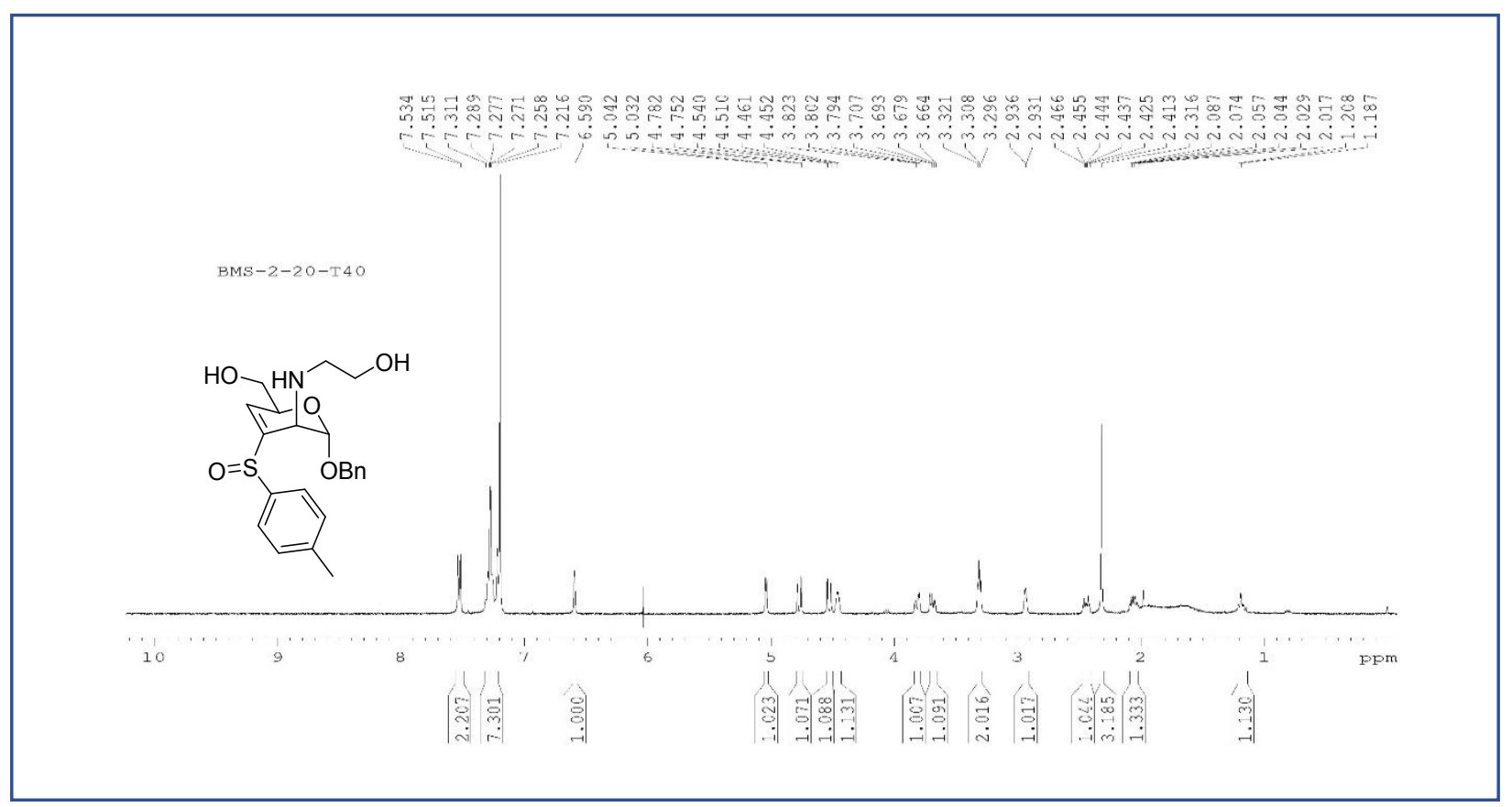

Figure S2. ${ }^{1} \mathrm{H}$ NMR spectrum of $5\left(\mathrm{CDCl}_{3}, 400 \mathrm{MHz}\right)$. 


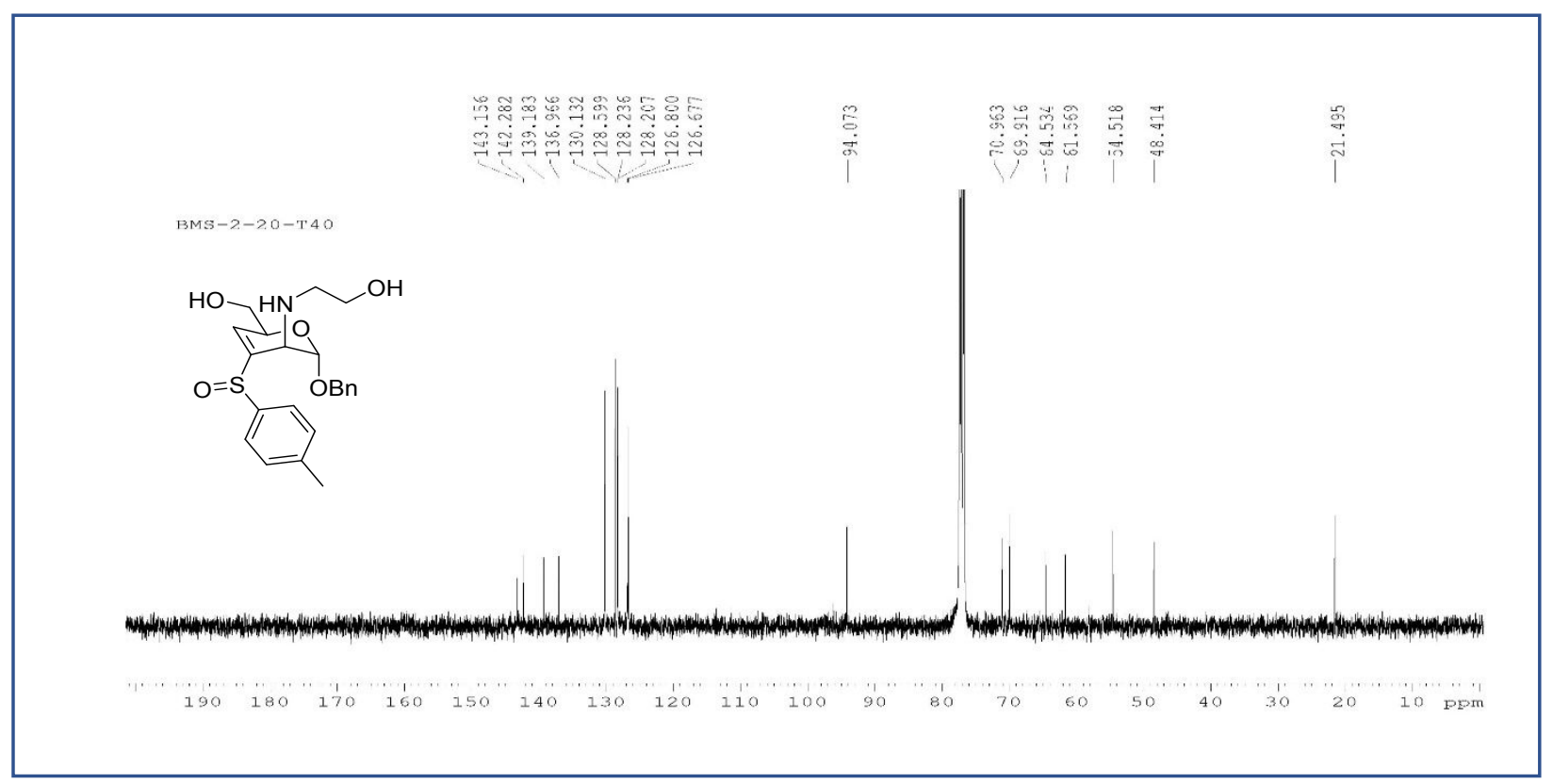

Figure S3. ${ }^{13} \mathrm{C}$ NMR spectrum of $5\left(\mathrm{CDCl}_{3}, 100 \mathrm{MHz}\right)$.

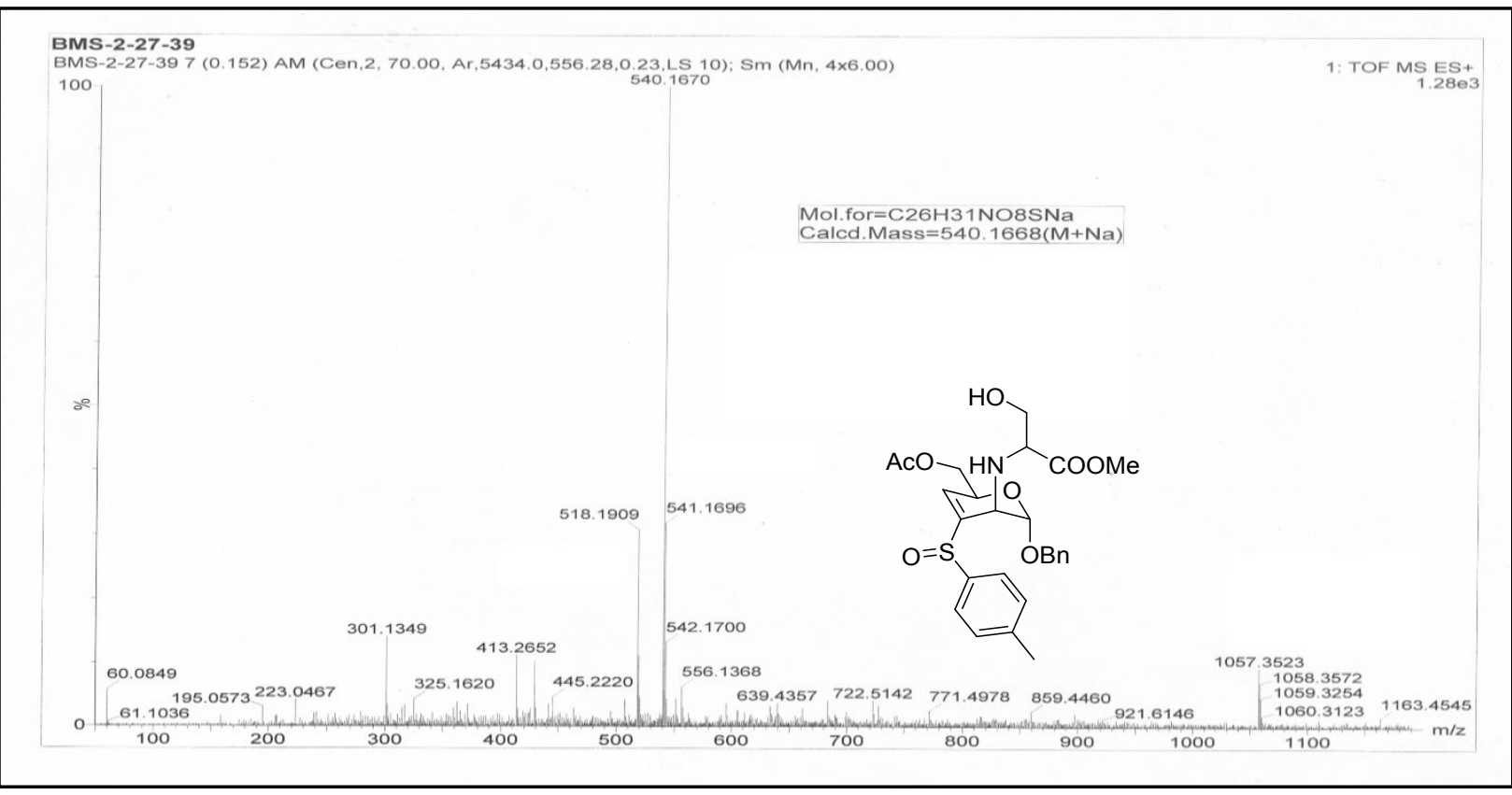

Figure S4. ESI-MS spectrum of 7. 


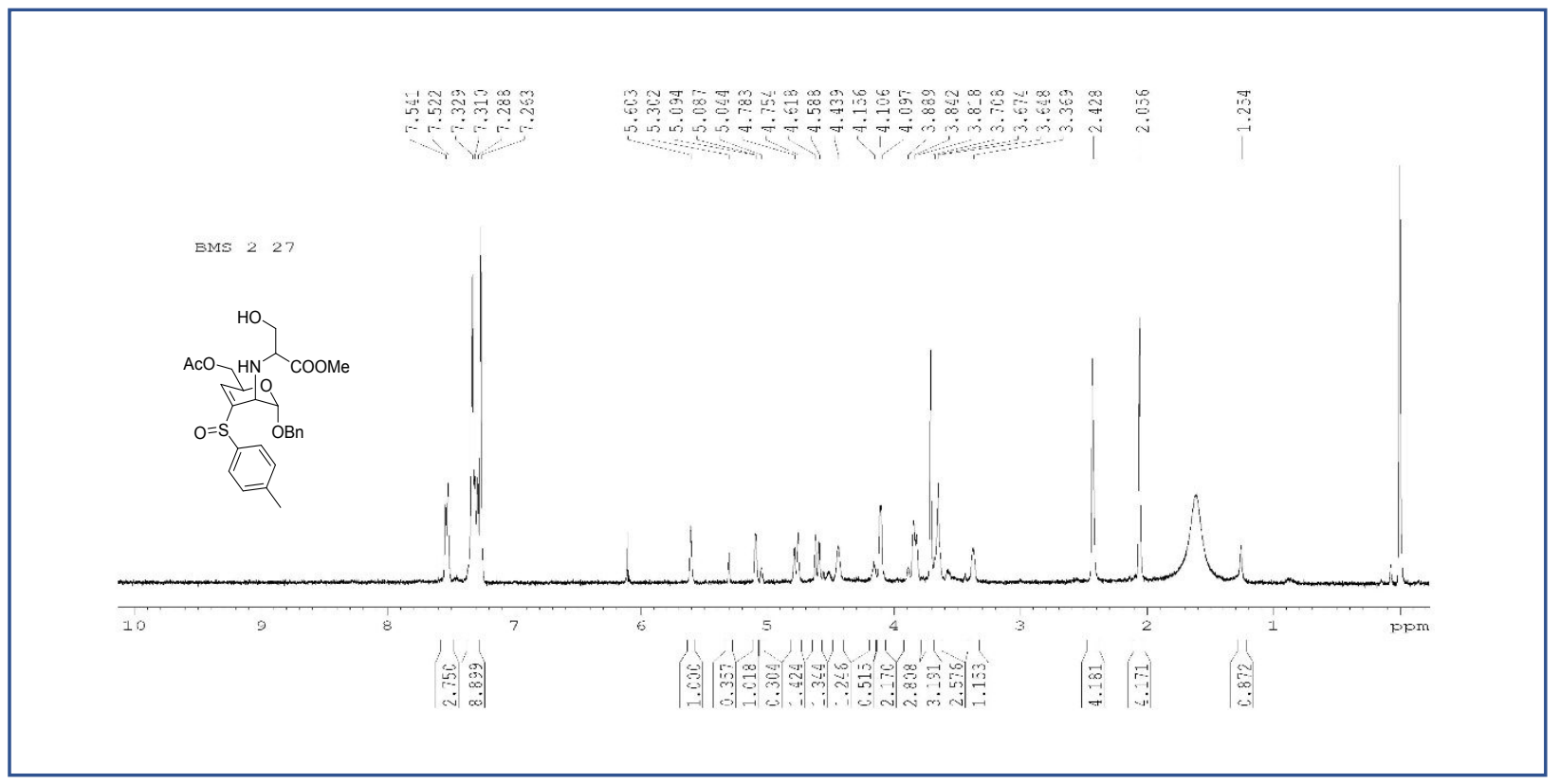

Figure S5. ${ }^{1} \mathrm{H}$ NMR spectrum of $7\left(\mathrm{CDCl}_{3}, 400 \mathrm{MHz}\right)$.

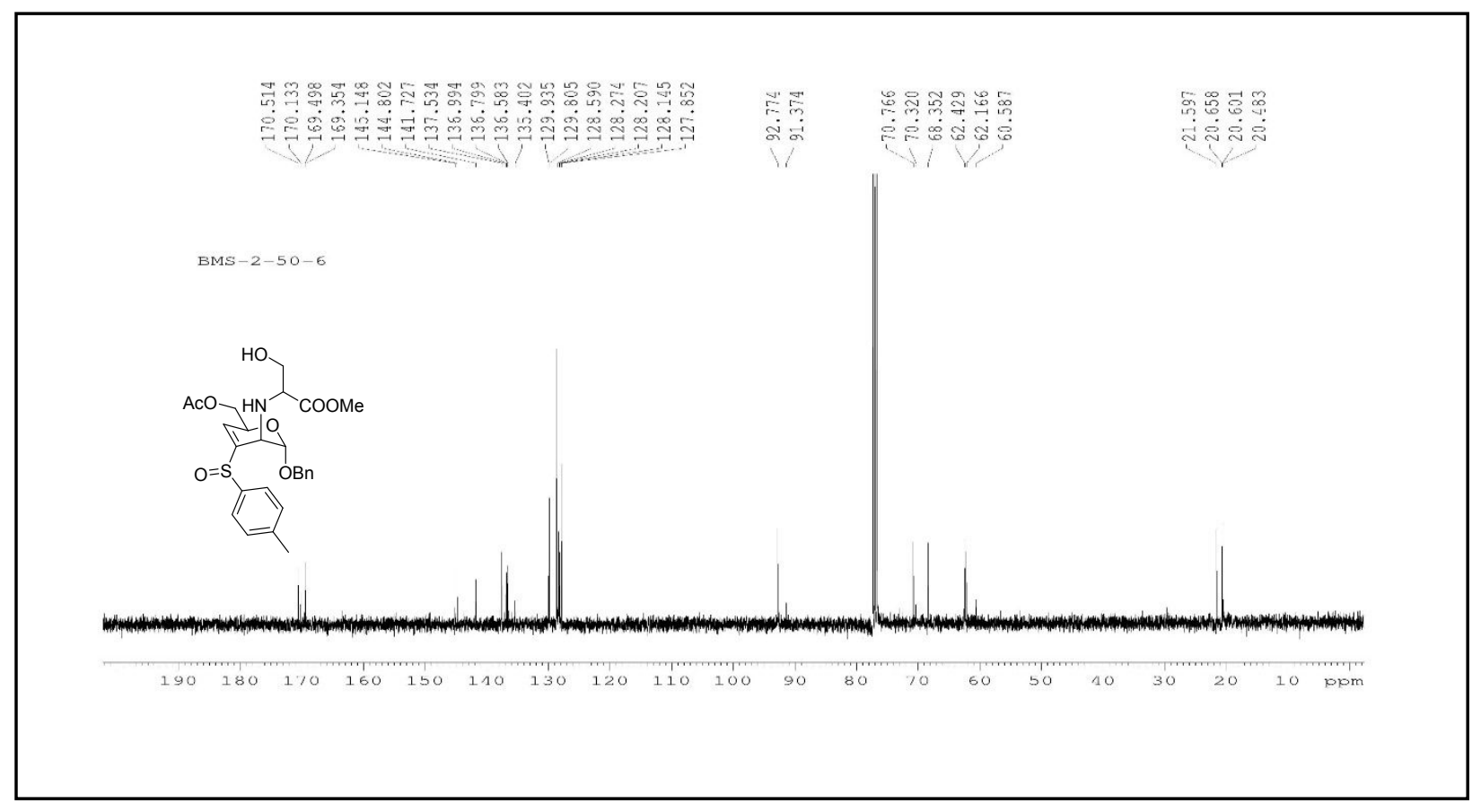

Figure S6. ${ }^{13} \mathrm{C} \mathrm{NMR}$ spectrum of $7\left(\mathrm{CDCl}_{3}, 100 \mathrm{MHz}\right)$. 


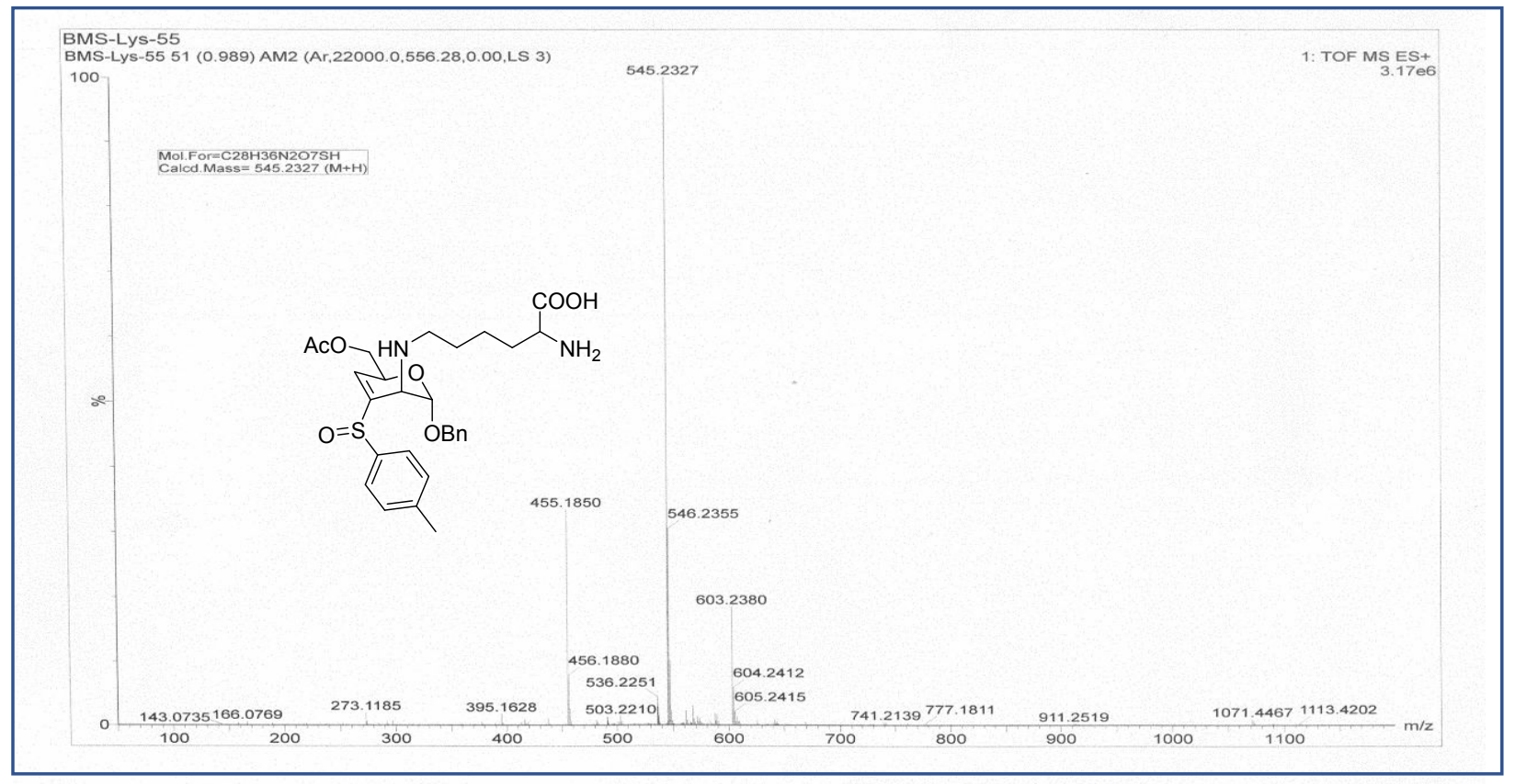

Figure S7. ESI-MS spectrum of 9.

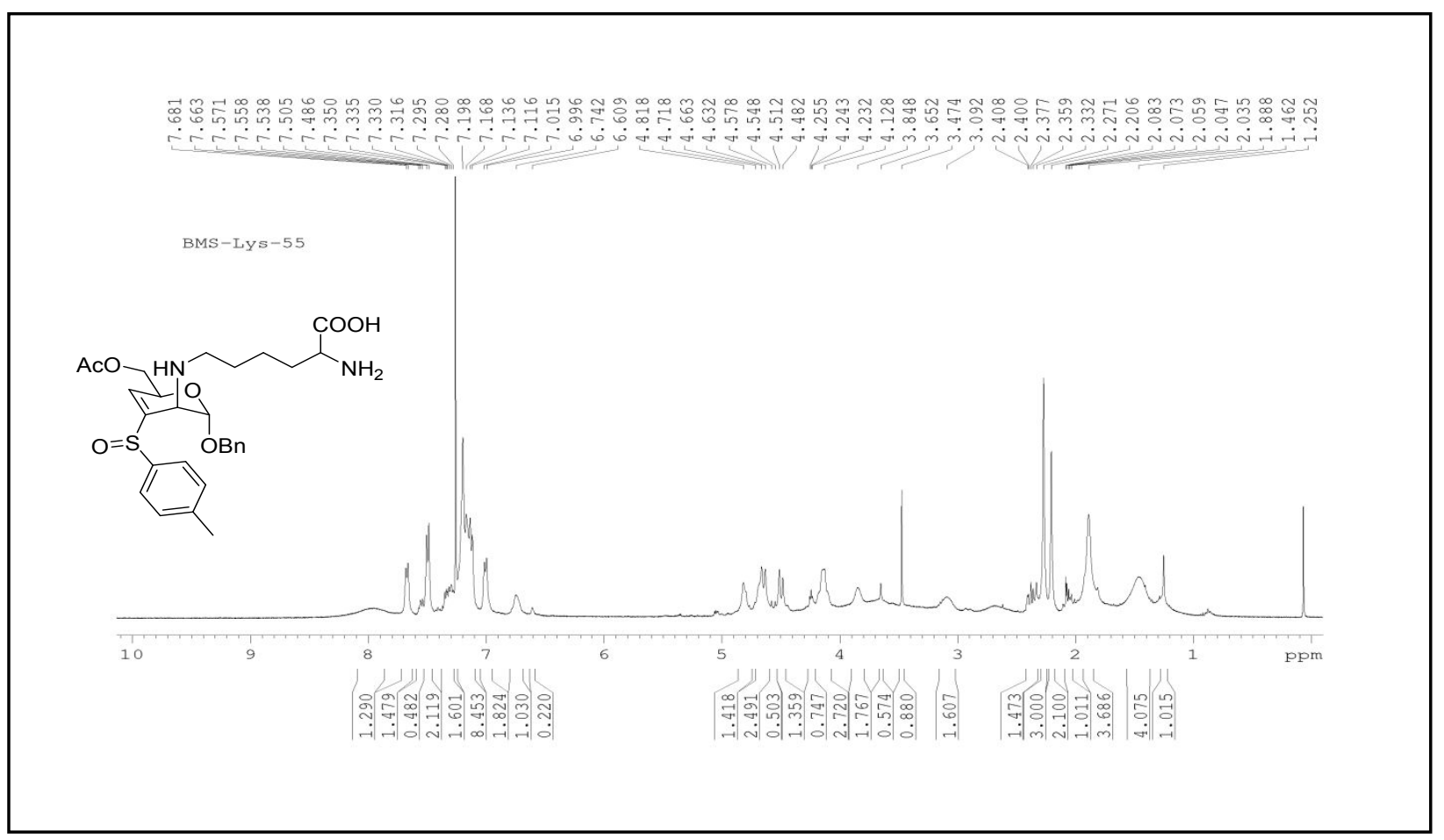

Figure S8. ${ }^{1} \mathrm{H}$ NMR spectrum of $9\left(\mathrm{CDCl}_{3}, 400 \mathrm{MHz}\right)$. 


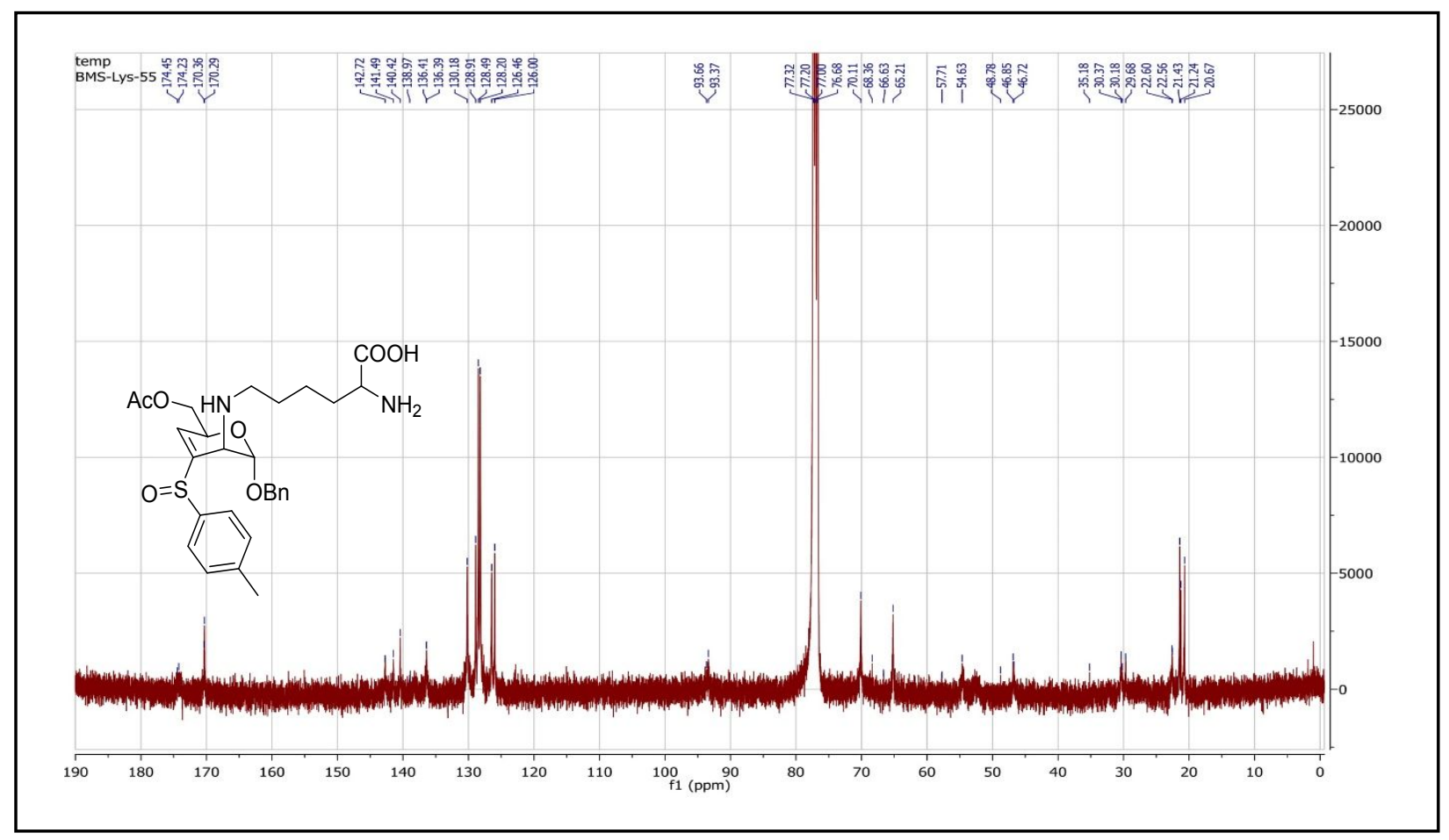

Figure S9. ${ }^{13} \mathrm{C} \mathrm{NMR}$ spectrum of $9\left(\mathrm{CDCl}_{3}, 100 \mathrm{MHz}\right)$.

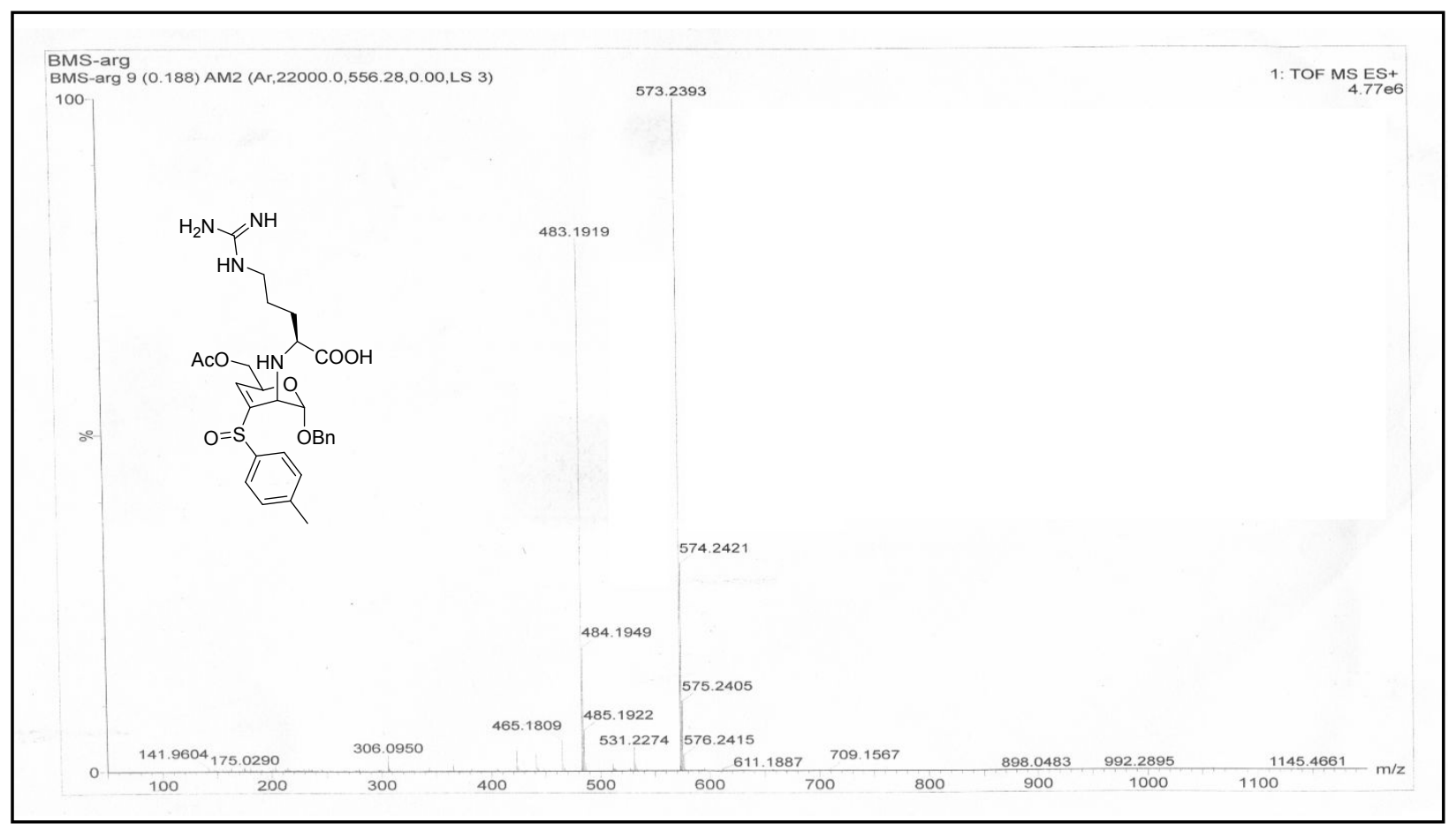

Figure S10. ESI-MS spectrum of 11. 


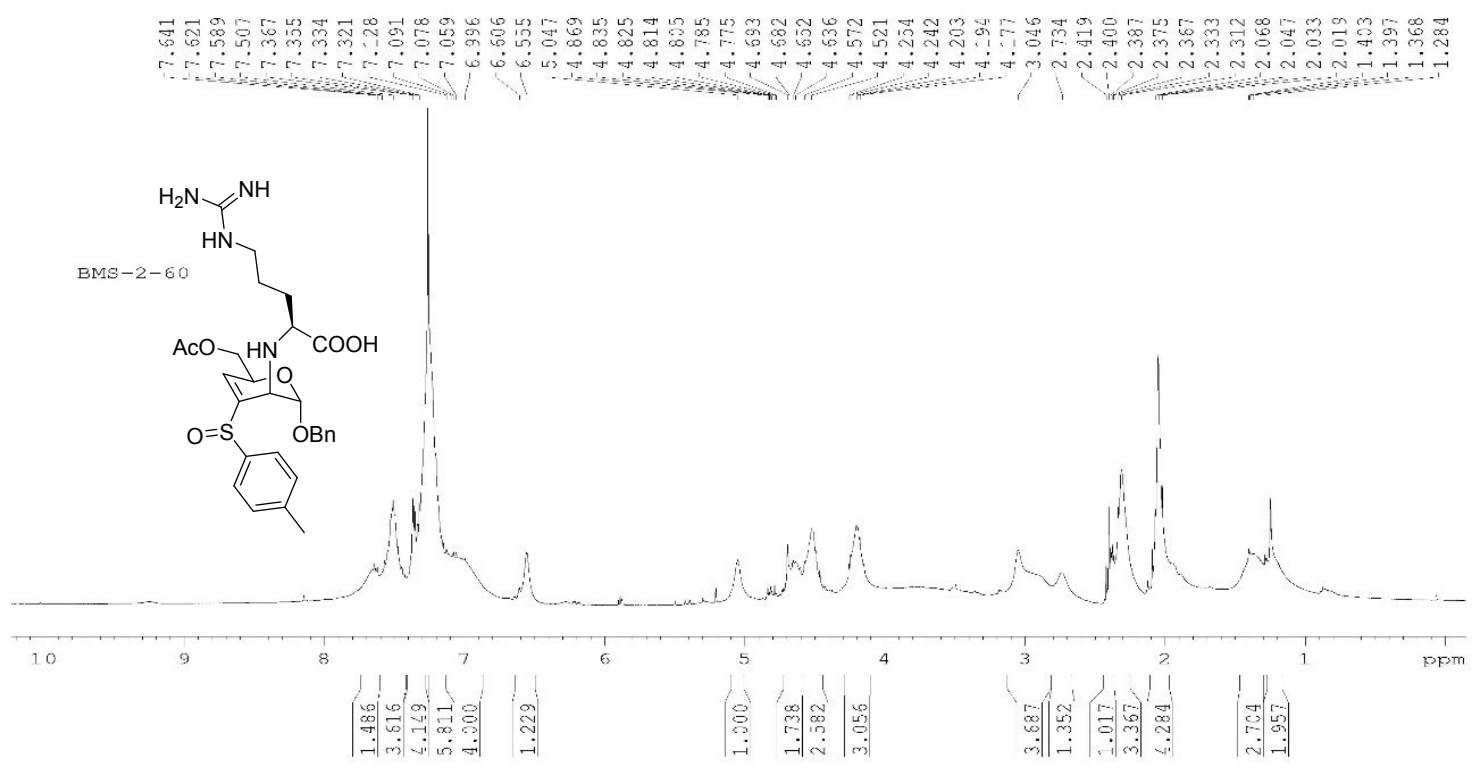

Figure S11. ${ }^{1} \mathrm{H}$ NMR spectrum of $11\left(\mathrm{CDCl}_{3}, 400 \mathrm{MHz}\right)$.

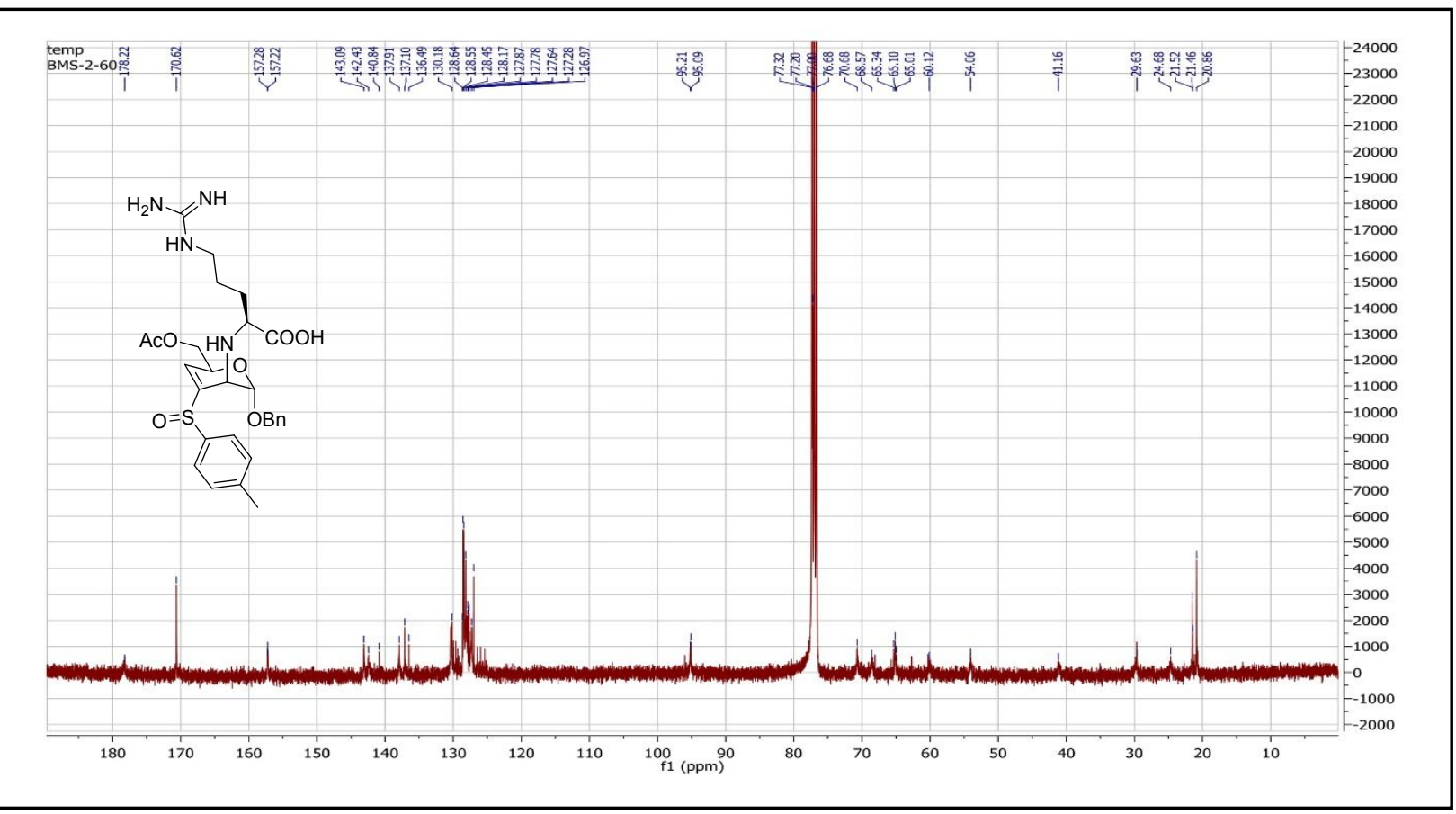

Figure S12. ${ }^{13} \mathrm{C}$ NMR spectrum of $11\left(\mathrm{CDCl}_{3}, 100 \mathrm{MHz}\right)$. 


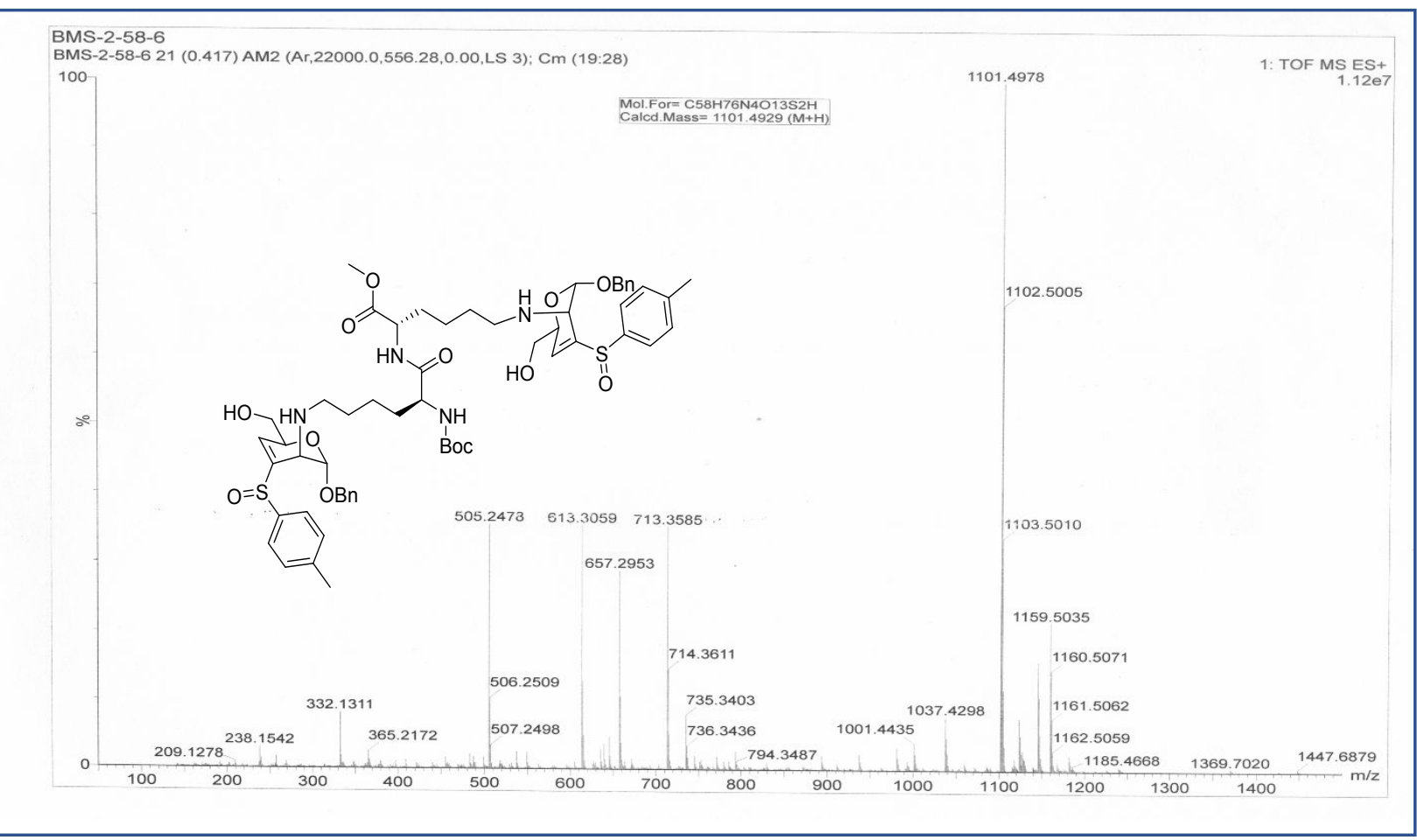

Figure S13. ESI-MS spectrum of 14.

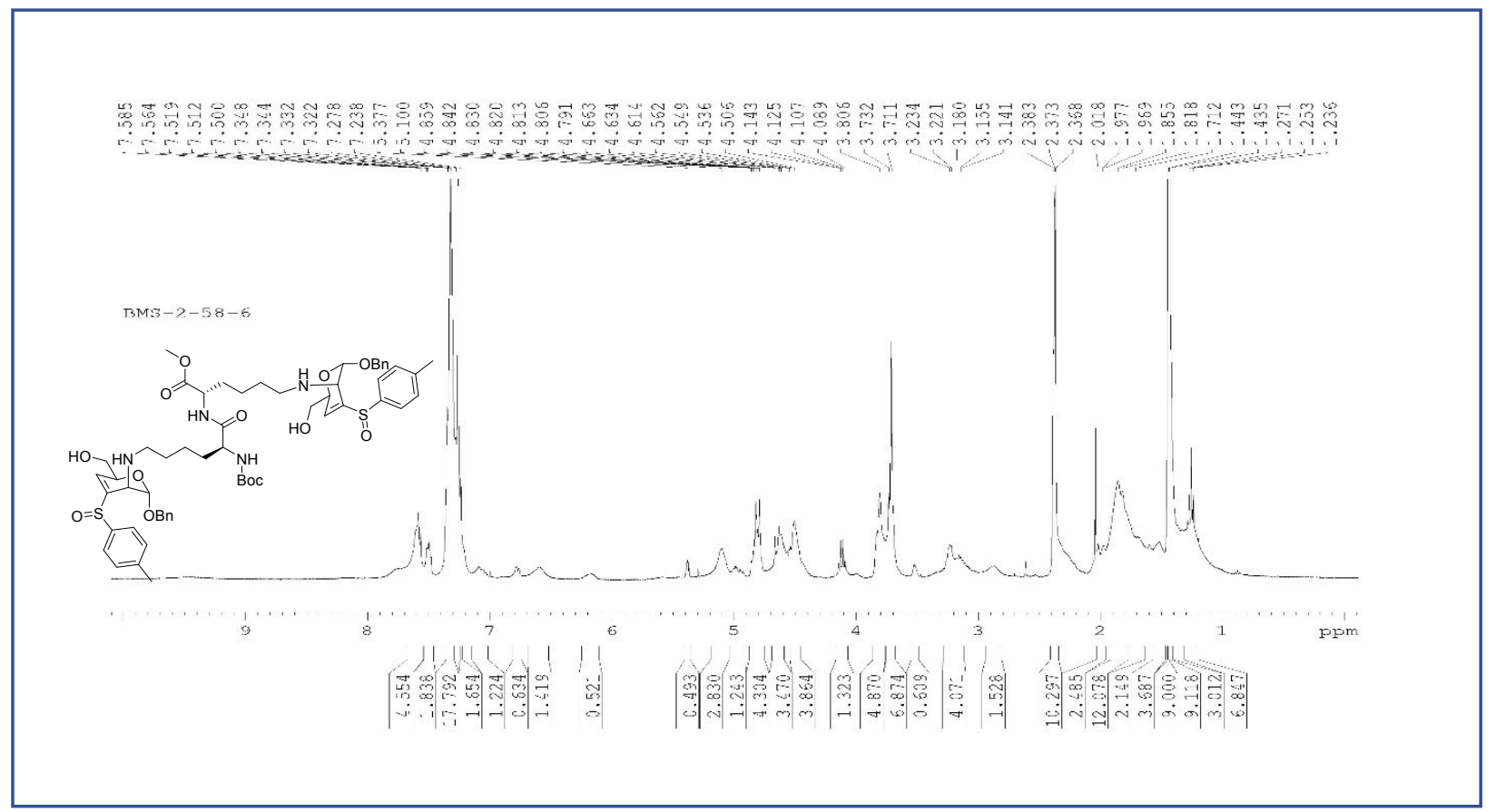

Figure S14. ${ }^{1} \mathrm{H}$ NMR spectrum of $14\left(\mathrm{CDCl}_{3}, 400 \mathrm{MHz}\right)$. 


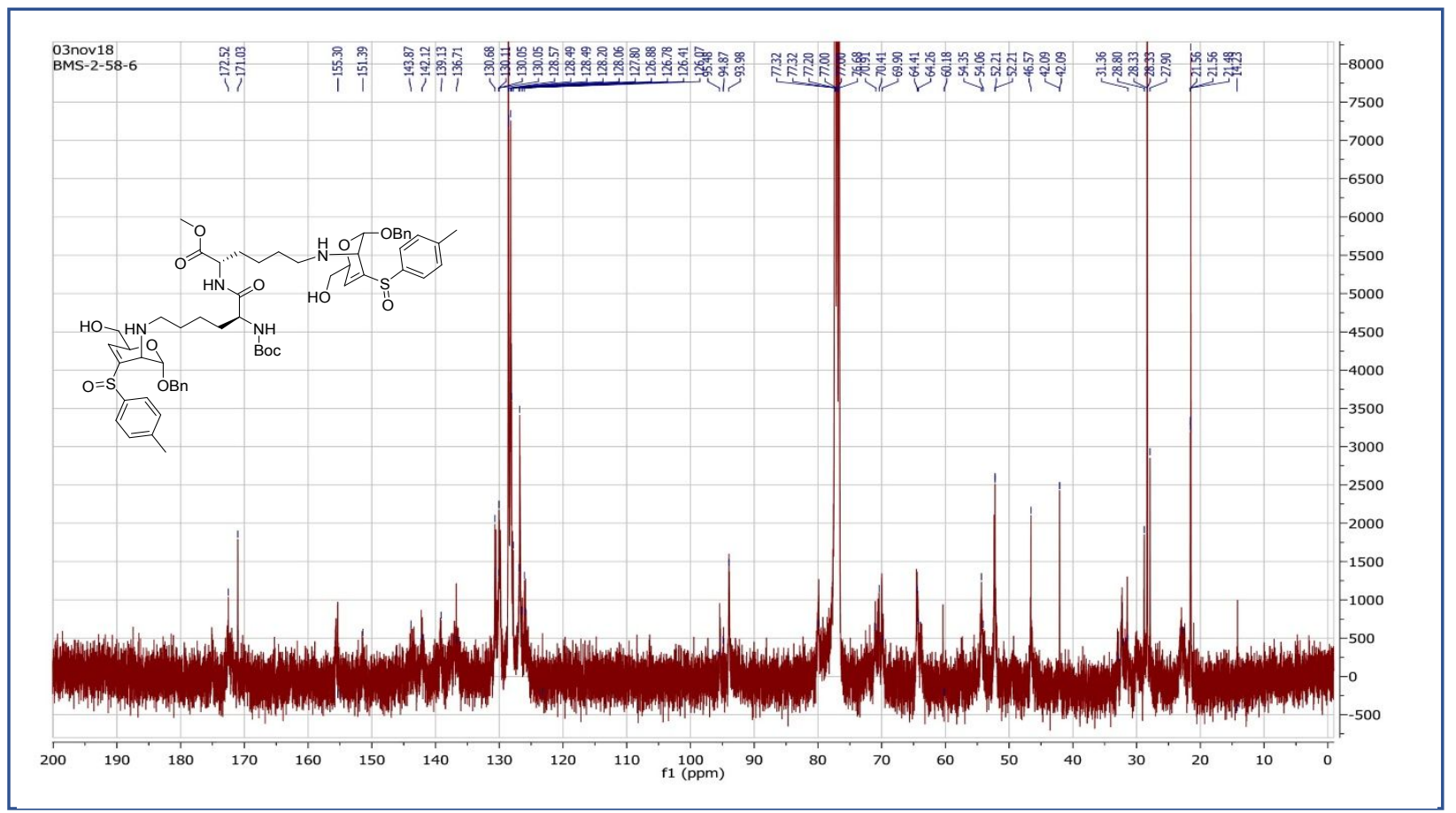

Figure S15. ${ }^{13} \mathrm{C}$ NMR spectrum of $14\left(\mathrm{CDCl}_{3}, 100 \mathrm{MHz}\right)$.

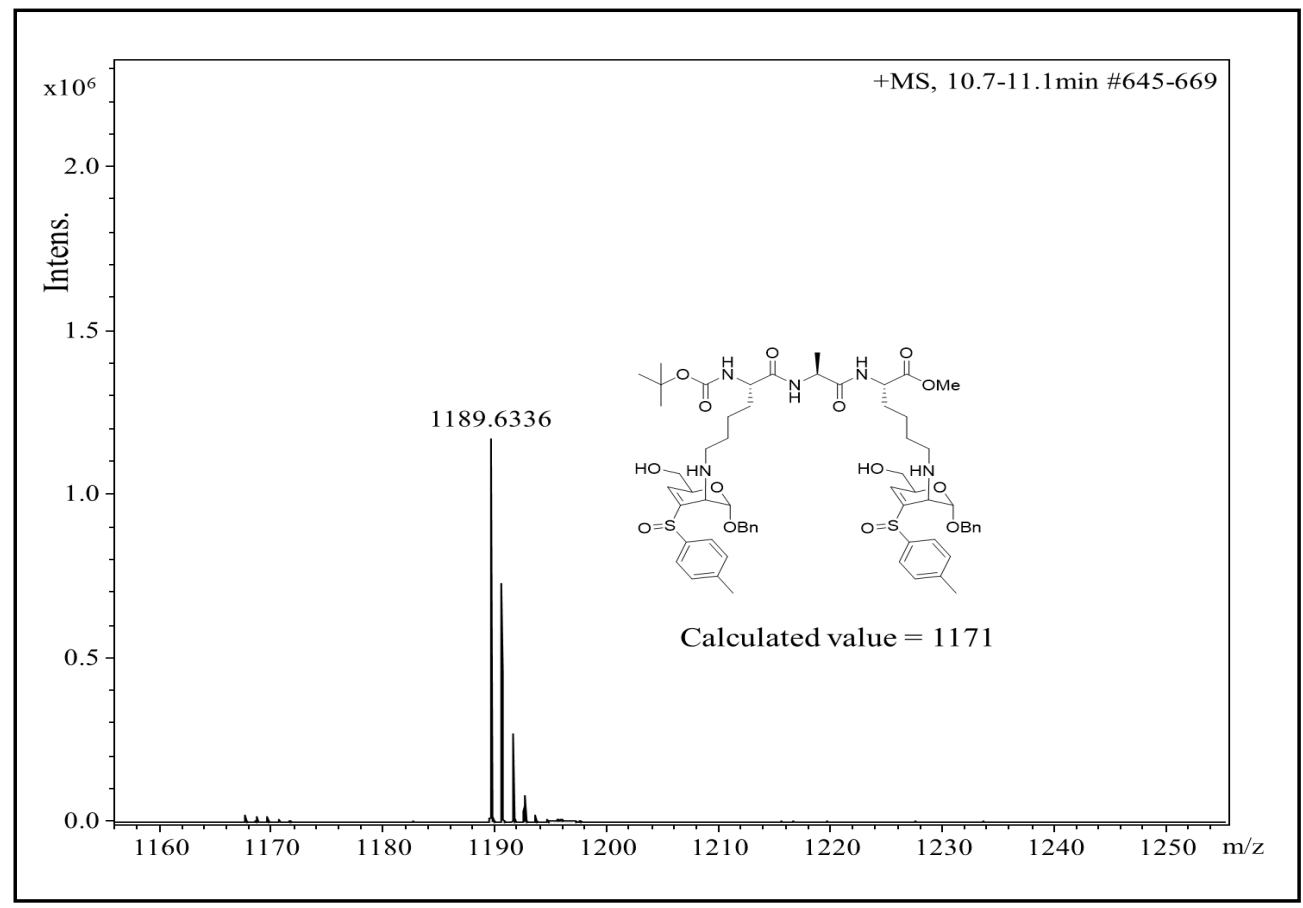

Figure S16. LCMS spectrum of $\mathbf{1 5 .}$ 


\section{Protein Mass Spectrometry}

The protein analyses were performed on HCT Ultra PTM Discovery LCMS System (ETD IIBruker Daltonics), connected with 1100 series HPLC (Agilent). Agilent Poroshell 120 SB-C 18 (4.6 x $250 \mathrm{~mm}$ ), paticle size $2.7 \mu \mathrm{m}$ column was used for LCMS. HRMS data were recorded on Bruker Daltonics MicroTOF-Q-II with electrospray ionization (ESI). MALDI-TOF/TOF mass spectrometry was performed with Bruker Daltonics UltrafleXtreme. Peptide mass and fragment were analyzed using Bruker Daltonics Sequence Editor 3.2 for peptide mapping and sequencing.

\section{Methods and Solvents for LCMS}

A mixture of acetonitrile and $\mathrm{H}_{2} \mathrm{O}$ containing formic acid $(0.01 \%)$ was used as the mobile phase in LCMS analysis. Following two methods of solvent gradient system were used in the analysis.

\section{Method A}

Column: Agilent Poroshell $120 \mathrm{SB}_{18}(4.6 \times 250 \mathrm{~mm})$, particle size $2.7 \mu \mathrm{m}$, flow rate 0.2 $\mathrm{ml} / \mathrm{min}$.

Table S1. Method A for LCMS analysis.

\begin{tabular}{|l|l|l|}
\hline Time & $\mathrm{H}_{2} \mathrm{O}(\%)$ & Acetonitrile (\%) \\
\hline 0 & 95 & 5 \\
\hline 5 & 95 & 5 \\
\hline 20 & 5 & 95 \\
\hline 25 & 5 & 95 \\
\hline 30 & 95 & 5 \\
\hline
\end{tabular}




\section{Method B}

Column: Agilent Poroshell $120 \mathrm{SB}-\mathrm{C}_{18}(4.6 \times 250 \mathrm{~mm})$, particle size $2.7 \mu \mathrm{m}$, flow rate 0.2 $\mathrm{ml} / \mathrm{min}$.

Table S2. Method B for LCMS analysis.

\begin{tabular}{|l|l|l|}
\hline Time & $\mathrm{H}_{2} \mathrm{O}(\%)$ & Acetonitrile (\%) \\
\hline 0 & 90 & 10 \\
\hline 10 & 70 & 30 \\
\hline 30 & 10 & 90 \\
\hline 35 & 10 & 90 \\
\hline 40 & 90 & 10 \\
\hline
\end{tabular}

\section{Modification of Lysozyme}

A mixture of benzyl 4,6-di-O-acetyl-2,3-dideoxy-3-(p-tolylsulfinyl)- $\alpha$-D-erythro-hex-3enopyranoside (4 mg, $8.7 \mu \mathrm{mol})$, lysozyme (4.7 mg, $0.3 \mu \mathrm{mol})$ (PDB ID: 1DPX_A) and $\mathrm{NaHCO}_{3}$ $(1 \mathrm{mg})$ was dissolved in aq. $\mathrm{MeOH}(40 \%)(5 \mathrm{~mL})$ and incubated at $37{ }^{\circ} \mathrm{C}$ for $24 \mathrm{~h}$. The reaction mixture was taken for further analysis by MALDI-TOFMS, LCMS, SDS-PAGE and trypsin digestion analysis. In LCMS analysis, the modified lysozyme monomer eluted between 22.9 and 23.8 min. and dimer eluted between 19.2 and 19.9 minutes, under method B. Native lysozyme eluted between 5.2-5.6 minutes, under method B. 


\section{In-Gel Tryptic Digestion Protocol}

In-gel tryptic digestions for lysozyme and modified lysozyme were carried out by the following protocol, with modifications. ${ }^{1}$ Samples containing gel pieces were minced into small pieces and transferred into a sterile microcentrifuge tube, washed with wash solution aq. acetonitrile containing aq. ammonium bicarbonate $(50 \mathrm{mM})$, incubated at room temperature for $15 \mathrm{~min}$. with gentle agitation and dehydrated in acetonitrile for $5 \mathrm{~min}$. Gel pieces were then rehydrated in reduction solution containing dithiothreitol $(10 \mathrm{mM})$ in aq. ammonium bicarbonate $(50 \mathrm{mM})$ for 30 min. at $56{ }^{\circ} \mathrm{C}$. After discarding reduction solution, alkylation solution (iodoacetamide (50 $\mathrm{mM})$ in aq. ammonium bicarbonate $(50 \mathrm{mM}))$ was added to gel pieces, incubated for $30 \mathrm{~min}$. in dark at room temperature, alkylation solution discarded, washed with wash solution and incubated again for $15 \mathrm{~min}$. at room temperature with gentle agitation. The gel pieces was again dehydrated gel in acetonitrile for $5 \mathrm{~min}$., dried and samples allowed for tryptic digestion $(20 \mu \mathrm{g}$ $\mathrm{mL}^{-1}$ ) for $15 \mathrm{~h}$ at $37^{\circ} \mathrm{C}$. After digestion, samples were centrifuged at a speed of $12,000 \mathrm{rpm}$ for 30 sec. Supernatant was collected, the gel pieces were dipped into the extraction solution (trifluoroacetic acid (0.1\%) and acetonitrile (50\%)), sonicated for $10 \mathrm{~min}$, centrifuged, supernatants combined and evaporated by centrifugal evaporation. A re-suspension solution (5 $\mu \mathrm{L})$ was added to each tube, sonicated and/or agitated gently on a vortex. The samples were subjected for MALDI-TOF analysis (alpha-cyano-4-hydroxycinnamic acid matrix). The unknown samples were calibrated using internal tryptic peaks of 842.5 and 2211.1 Da. 


\section{LCMS Data of Native Lysozyme}

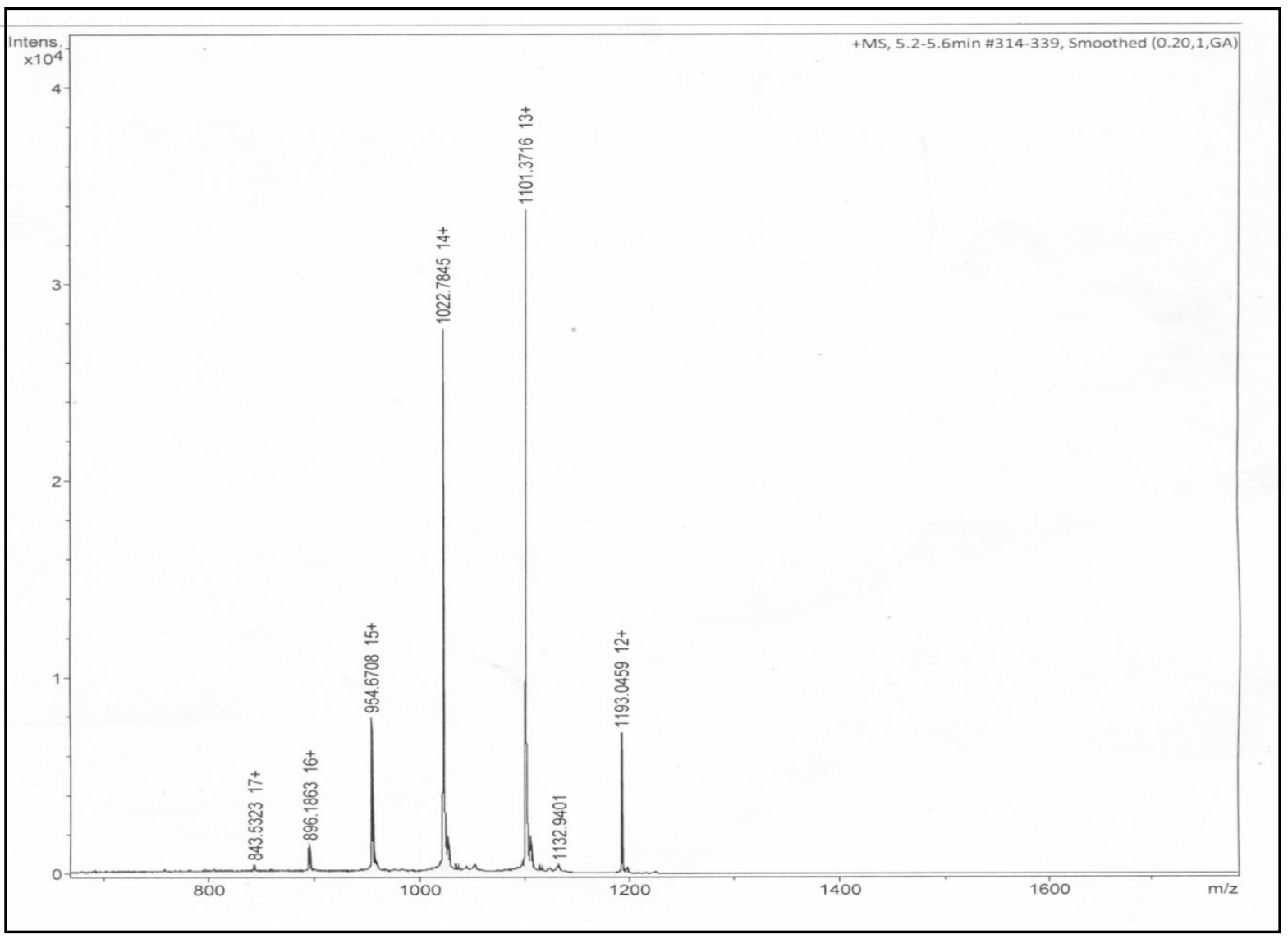

Figure S17. LCMS spectrum of native lysozyme.

Table S3. LCMS data of native lysozyme.

\begin{tabular}{|l|l|l|l|}
\hline Component & Mass & Molecule & Abund. [\%] \\
\hline A & 14304.7943 & $\mathrm{Mr}$ & 100.00 \\
\hline B & 14322.1509 & $\mathrm{Mr}$ & 24.02 \\
\hline $\mathrm{C}$ & 14362.4472 & $\mathrm{Mr}$ & 7.73 \\
\hline
\end{tabular}

Abbreviation: $\mathrm{Mr}=$ molecular ion 


\section{LCMS Spectrum and Data of Modified Lysozyme}

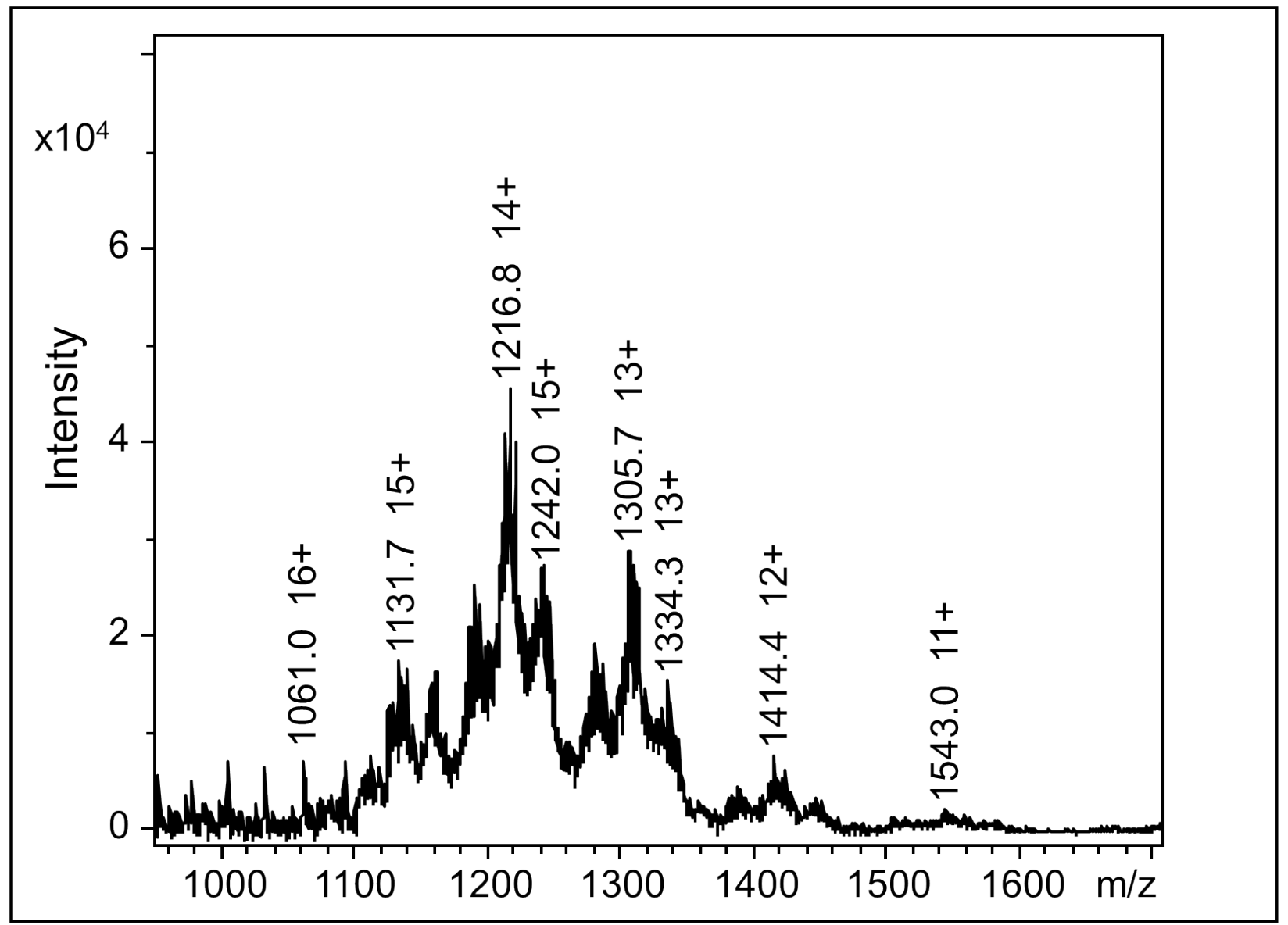

Figure S18. LCMS spectrum of modified Lysozyme.

Table S4. LCMS data of modified lysozyme.

$\begin{array}{llll}\text { Component } & \text { Mass } & \text { Molecule } & \text { Abund. [\%] } \\ \text { A } & 17021.6 & \mathrm{Mr} & 99 \\ \mathrm{~B} & 15788.8 & \mathrm{Mr} & 69 \\ \mathrm{C} & 16960.9 & \mathrm{Mr} & 100 \\ \mathrm{D} & 17063.1 & \mathrm{Mr} & 88 \\ \mathrm{E} & 15827.8 & \mathrm{Mr} & 62 \\ \mathrm{~F} & 15733.1 & \mathrm{Mr} & 71 \\ \mathrm{G} & 16918.0 & \mathrm{Mr} & 68 \\ \mathrm{H} & 18615.7 & \mathrm{Mr} & 51 \\ \mathrm{I} & 15693.2 & \mathrm{Mr} & 61 \\ \mathrm{~J} & 17333.2 & \mathrm{Mr} & 60\end{array}$

Abbreviation: $\mathrm{Mr}=$ Molecular ion 


\section{LCMS Spectrum and Data of Native Lysozyme after Trypsin Digestion}

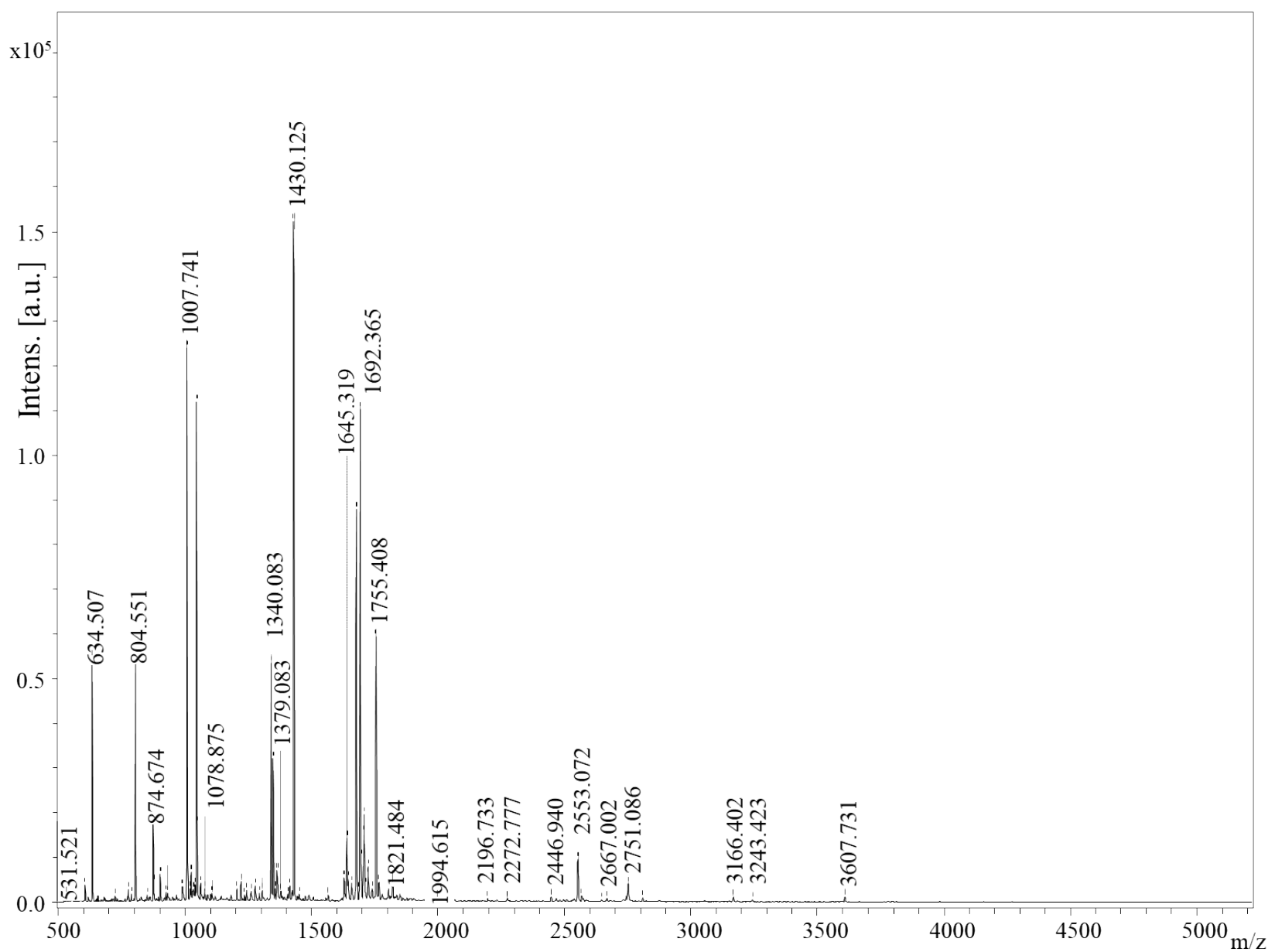

Figure S19. LCMS spectrum of native lysozyme after trypsin digestion.

Table S5. LCMS data of native lysozyme after trypsin digestion.

$\begin{array}{llllll}\boldsymbol{m} / \boldsymbol{z} & \mathbf{S} / \mathbf{N} & \text { Quality Fac. } & \text { Res. } & \text { Intens. } & \text { Area } \\ 531.521 & 12 & 3254 & 2479 & 1678 & 546 \\ 550.813 & 10 & 8402 & 3316 & 1408 & 380 \\ 606.477 & 28 & 31071 & 2873 & 3996 & 1447 \\ 634.507 & 371 & 340589 & 3395 & 54389 & 17116 \\ 636.504 & 12 & 3911 & 2933 & 1798 & 685 \\ 724.571 & 9 & 826 & 3954 & 1434 & 457 \\ 776.509 & 18 & 9000 & 3991 & 2775 & 980 \\ 788.658 & 11 & 3211 & 2652 & 1792 & 936\end{array}$




\begin{tabular}{|c|c|c|c|c|c|}
\hline 804.551 & 354 & 80737 & 3791 & 56173 & 21857 \\
\hline 806.561 & 41 & 45047 & 3749 & 6473 & 2574 \\
\hline 851.587 & 9 & 2438 & 4162 & 1414 & 538 \\
\hline 874.674 & 117 & 46092 & 4311 & 19547 & 7695 \\
\hline 879.615 & 10 & 3696 & 4149 & 1587 & 660 \\
\hline 902.72 & 38 & 26166 & 3484 & 6356 & 3263 \\
\hline 904.669 & 9 & 1770 & 2824 & 1518 & 1005 \\
\hline 925.659 & 11 & 7462 & 1695 & 1849 & 2025 \\
\hline 932.708 & 12 & 963 & 4772 & 2044 & 793 \\
\hline 988.829 & 11 & 878 & 5074 & 1969 & 763 \\
\hline 989.778 & 14 & 2759 & 3599 & 2482 & 1341 \\
\hline 990.689 & 14 & 172 & 5703 & 2395 & 795 \\
\hline 992.699 & 10 & 488 & 4385 & 1695 & 759 \\
\hline 1005.717 & 16 & 138 & 4057 & 2794 & 1499 \\
\hline 1007.741 & 648 & 464201 & 3583 & 113843 & 68121 \\
\hline 1008.755 & 361 & 185935 & 3742 & 63415 & 33583 \\
\hline 1009.737 & 65 & 36236 & 3931 & 11344 & 6244 \\
\hline 1011.746 & 22 & 4669 & 3885 & 3923 & 2143 \\
\hline 1019.753 & 17 & 2996 & 4444 & 2974 & 1399 \\
\hline 1023.755 & 29 & 37225 & 4304 & 5224 & 2603 \\
\hline 1024.747 & 21 & 3609 & 4354 & 3759 & 1800 \\
\hline 1030.793 & 13 & 1849 & 3379 & 2363 & 1487 \\
\hline 1033.82 & 12 & 1677 & 3285 & 2124 & 1480 \\
\hline 1039.713 & 15 & 3274 & 4305 & 2732 & 1490 \\
\hline 1040.716 & 8 & 307 & 4489 & 1476 & 754 \\
\hline 1045.9 & 542 & 114293 & 3235 & 97031 & 69667 \\
\hline 1046.94 & 333 & 5097 & 3715 & 59671 & 32408 \\
\hline 1049.892 & 21 & 3192 & 2403 & 3805 & 3667 \\
\hline 1061.912 & 15 & 6225 & 4402 & 2743 & 1382 \\
\hline 1062.909 & 14 & 1225 & 4368 & 2483 & 1228 \\
\hline 1077.887 & 10 & 625 & 4803 & 1799 & 843 \\
\hline 1078.875 & 10 & 2023 & 4010 & 1889 & 1113 \\
\hline 1102.784 & 7 & 1593 & 3439 & 1379 & 1058 \\
\hline 1106.884 & 9 & 1715 & 3570 & 1623 & 1169 \\
\hline 1204.97 & 15 & 1744 & 4772 & 3007 & 1801 \\
\hline 1220.966 & 22 & 6620 & 4568 & 4275 & 2709 \\
\hline 1235.005 & 7 & 1007 & 4419 & 1460 & 1006 \\
\hline 1244.055 & 11 & 2432 & 3436 & 2246 & 2031 \\
\hline 1262.012 & 11 & 945 & 4775 & 2226 & 1432 \\
\hline 1278.023 & 17 & 5273 & 4833 & 3333 & 2164 \\
\hline 1294.044 & 7 & 2547 & 3835 & 1494 & 1275 \\
\hline 1305.59 & 10 & 1999 & 2120 & 2109 & 3512 \\
\hline 1340.083 & 189 & 60410 & 4799 & 38421 & 27690 \\
\hline
\end{tabular}




\begin{tabular}{|c|c|c|c|c|c|}
\hline 1341.102 & 133 & 2909 & 5915 & 27068 & 14103 \\
\hline 1342.087 & 25 & 1913 & 4923 & 4978 & 3350 \\
\hline 1348.145 & 87 & 8128 & 6429 & 17594 & 9288 \\
\hline 1349.138 & 111 & 34437 & 4947 & 22565 & 15658 \\
\hline 1356.096 & 13 & 2831 & 4878 & 2579 & 1868 \\
\hline 1362.059 & 15 & 1198 & 4221 & 3084 & 2644 \\
\hline 1364.12 & 27 & 6471 & 4144 & 5515 & 4807 \\
\hline 1366.157 & 14 & 244 & 7528 & 2844 & 1240 \\
\hline 1367.126 & 12 & 2757 & 4656 & 2392 & 1852 \\
\hline 1379.083 & 10 & 1865 & 4516 & 2094 & 1666 \\
\hline 1406.14 & 7 & 3863 & 4037 & 1375 & 1359 \\
\hline 1412.078 & 12 & 940 & 5181 & 2415 & 1771 \\
\hline 1414.069 & 13 & 943 & 3130 & 2574 & 3142 \\
\hline 1428.082 & 210 & 407 & 4011 & 42016 & 45209 \\
\hline 1430.125 & 750 & 122053 & 3809 & 149836 & 153712 \\
\hline 1452.084 & 8 & 7215 & 4906 & 1521 & 1244 \\
\hline 1566.17 & 7 & 7148 & 4525 & 1362 & 1425 \\
\hline 1628.315 & 23 & 14742 & 4813 & 4324 & 4700 \\
\hline 1630.321 & 9 & 554 & 5384 & 1696 & 1417 \\
\hline 1639.239 & 56 & 4126 & 3331 & 10175 & 16733 \\
\hline 1640.334 & 34 & 460 & 13297 & 6284 & 2286 \\
\hline 1643.315 & 11 & 752 & 7535 & 1956 & 1294 \\
\hline 1645.319 & 23 & 60155 & 5419 & 4291 & 3996 \\
\hline 1659.302 & 22 & 19461 & 4983 & 3945 & 4244 \\
\hline 1675.353 & 16 & 9.26 & 5821 & 2813 & 2310 \\
\hline 1676.329 & 407 & 33251 & 4658 & 73673 & 87294 \\
\hline 1678.352 & 134 & 24345 & 5045 & 24325 & 23574 \\
\hline 1688.314 & 16 & 16.7 & 5109 & 2866 & 3272 \\
\hline 1692.365 & 505 & 23013 & 4190 & 90691 & 122576 \\
\hline 1694.4 & 198 & 2915 & 5413 & 35522 & 31468 \\
\hline 1698.346 & 11 & 5786 & 4062 & 1910 & 2663 \\
\hline 1704.399 & 16 & 440 & 5397 & 2811 & 2748 \\
\hline 1706.378 & 27 & 1394 & 5292 & 4870 & 4872 \\
\hline 1708.378 & 92 & 28378 & 4924 & 16280 & 18233 \\
\hline 1710.404 & 30 & 448 & 10439 & 5245 & 2548 \\
\hline 1714.344 & 8 & 2601 & 5455 & 1341 & 1326 \\
\hline 1720.393 & 9 & 431 & 6042 & 1660 & 1476 \\
\hline 1722.384 & 10 & 318 & 5722 & 1691 & 1568 \\
\hline 1724.38 & 38 & 13733 & 5322 & 6785 & 7057 \\
\hline 1739.335 & 9 & 586 & 2353 & 1340 & 3455 \\
\hline 1753.398 & 118 & 766 & 9555 & 20625 & 12923 \\
\hline 1755.408 & 290 & 366028 & 4432 & 50763 & 65538 \\
\hline 1766.374 & 20 & 11368 & 4740 & 3412 & 4472 \\
\hline
\end{tabular}




$\begin{array}{llllll}1805.499 & 10 & 7179 & 4229 & 1628 & 2346 \\ 1821.484 & 23 & 185489 & 4991 & 3811 & 4870 \\ 1984.571 & 1 & & 4790 & 324 & 129 \\ 2063.618 & 2 & & 4775 & 456 & 196 \\ 2196.733 & 3 & & 6072 & 766 & 317 \\ 2279.772 & 1 & & 4965 & 272 & 139 \\ 2446.94 & 4 & & 4645 & 892 & 494 \\ 2553.072 & 95 & 2748 & 3778 & 6141 & 14236 \\ 2567.925 & 17 & 3244 & 5050 & 978 & 2103 \\ 2662.051 & 2 & & 7353 & 246 & 88.2 \\ 2751.086 & 55 & 8351 & 4868 & 2484 & 6035 \\ 3166.402 & 9 & & 7243 & 808 & 471 \\ 3238.415 & 1 & & 10940 & 97.5 & 48.3 \\ 3607.731 & 17 & 9448 & 909 & 604 & \end{array}$

Abbreviation: $\mathrm{m} / \mathrm{z}=$ molecular ion / charge; $\mathrm{S} / \mathrm{N}=$ signal / noise; Quality Fac. = quality factor; Res. $=$ resolution; Intens. $=$ intensity 


\section{LCMS Spectrum and Data of Modified Lysozyme after Trypsin Digestion}

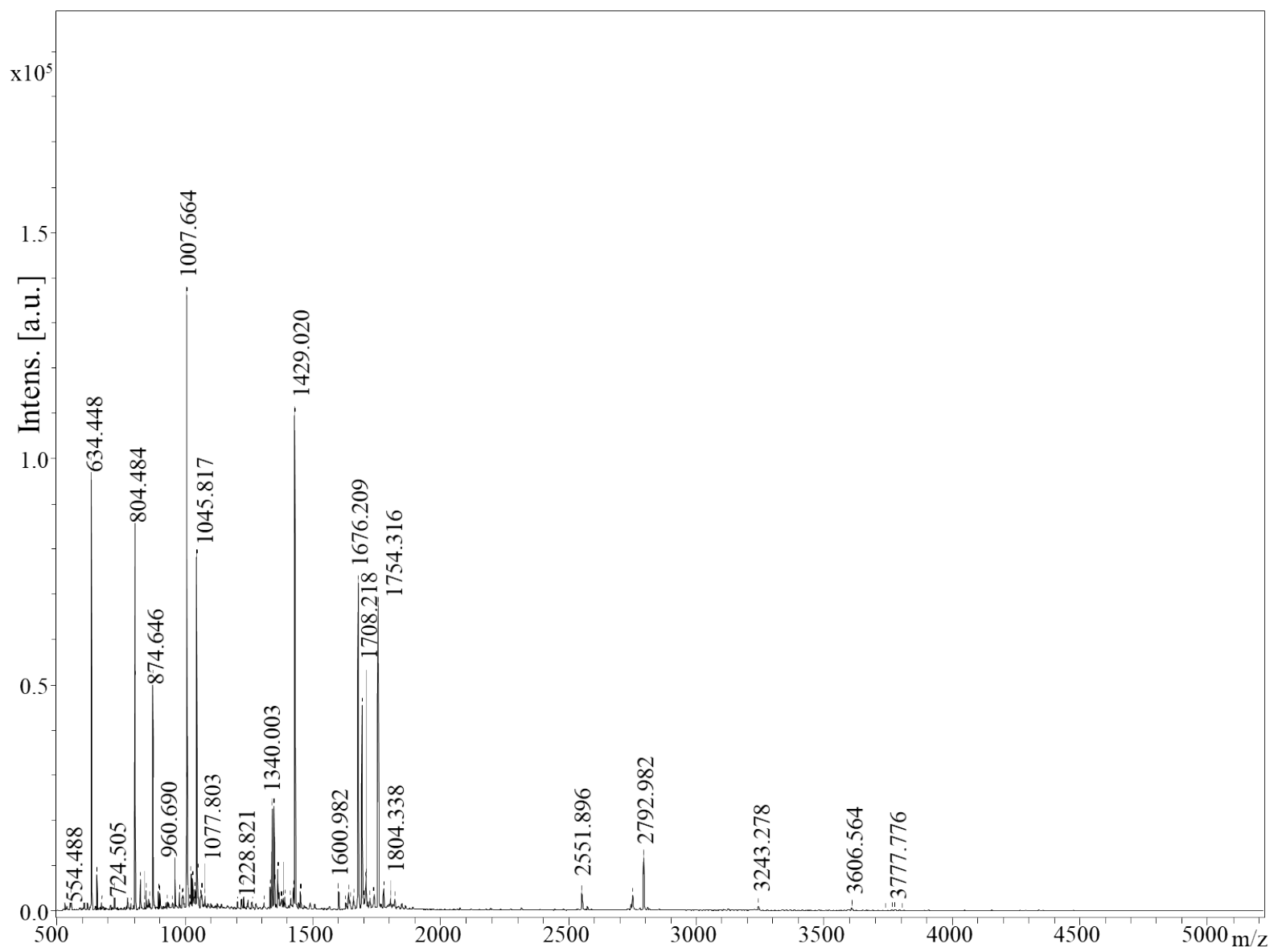

Figure S20. LCMS spectrum of modified lysozyme after trypsin digestion.

Table S6. LCMS data of modified lysozyme after trypsin digestion.

$m / z \quad$ S/N Quality Fac. Res. Intens. Area

$\begin{array}{llllll}531.471 & 10 & 2961 & 3513 & 1759 & 401 \\ 550.793 & 17 & 6037 & 5121 & 3051 & 500 \\ 554.488 & 18 & 9559 & 4319 & 3247 & 636 \\ 556.466 & 14 & 4865 & 4621 & 2396 & 430 \\ 606.506 & 48 & 10975 & 2409 & 8677 & 3276 \\ 618.433 & 14 & 11709 & 4098 & 2486 & 611 \\ 634.448 & 539 & 139177 & 4349 & 98860 & 23777 \\ 635.47 & 108 & 14711 & 5338 & 19757 & 3591 \\ 636.458 & 11 & 1977 & 3565 & 1948 & 596\end{array}$




$\begin{array}{llllll}656.426 & 41 & 16325 & 4463 & 7651 & 1915 \\ 672.403 & 9 & 5613 & 4846 & 1695 & 408 \\ 724.505 & 23 & 14164 & 5279 & 4401 & 1012 \\ 726.484 & 15 & 7317 & 5424 & 2856 & 639 \\ 776.445 & 22 & 10966 & 5391 & 4203 & 1071 \\ 788.513 & 9 & 6544 & 3223 & 1758 & 821 \\ 804.484 & 447 & 80199 & 5005 & 88712 & 25730 \\ 806.496 & 39 & 4142 & 5377 & 7660 & 2072 \\ 826.47 & 36 & 6078 & 5322 & 7203 & 2074 \\ 842.423 & 8 & 2119 & 4980 & 1705 & 581 \\ 848.445 & 23 & 6785 & 5806 & 4604 & 1245 \\ 859.619 & 13 & 1536 & 4793 & 2598 & 844 \\ 874.646 & 250 & 232425 & 4378 & 51728 & 19958 \\ 879.575 & 8 & 1945 & 4779 & 1562 & 534 \\ 896.641 & 21 & 27437 & 5909 & 4436 & 1214 \\ 902.645 & 20 & 3250 & 4278 & 4108 & 1747 \\ 932.654 & 9 & 777 & 5942 & 1992 & 580 \\ 951.59 & 8 & 992 & 5624 & 1739 & 625 \\ 960.69 & 56 & 19423 & 6096 & 12024 & 3770 \\ 978.724 & 17 & 41105 & 5699 & 3758 & 1282 \\ 989.66 & 11 & 5129 & 5108 & 2361 & 948 \\ 990.635 & 10 & 314 & 6754 & 2118 & 580 \\ 992.647 & 10 & 1469 & 6015 & 2260 & 725 \\ 1005.64 & 10 & 74.9 & 5194 & 2071 & 878 \\ 1007.66 & 619 & 319866 & 4764 & 134428 & 60600 \\ 1008.68 & 248 & 69056 & 4975 & 54010 & 22437 \\ 1009.71 & 55 & 15342 & 6450 & 12014 & 3789 \\ 1011.68 & 18 & 7595 & 4798 & 3861 & 1696 \\ 1019.69 & 9 & 277 & 5340 & 1979 & 724 \\ 1023.69 & 36 & 47904 & 5943 & 7831 & 2718 \\ 1029.68 & 32 & 6652 & 5071 & 7004 & 2995 \\ 1030.81 & 19 & 964 & 6024 & 4078 & 1348 \\ 1033.75 & 8 & 405 & 5276 & 1799 & 688 \\ 1039.68 & 21 & 5700 & 5749 & 4520 & 1690 \\ 1045.82 & 351 & 195642 & 5030 & 77087 & 34402 \\ 1046.81 & 128 & 51622 & 4340 & 28098 & 14764 \\ 1051.72 & 12 & 1307 & 5234 & 2680 & 1112 \\ 1061.83 & 13 & 1094 & 5514 & 2956 & 1146 \\ 1063.86 & 20 & 1930 & 5043 & 4326 & 1807 \\ 1067.79 & 16 & 2853 & 5858 & 3439 & 1234 \\ 1077.8 & 14 & 4049 & 5071 & 3104 & 1387\end{array}$




\begin{tabular}{|c|c|c|c|c|c|}
\hline 1079.79 & 9 & 4949 & 5291 & 2099 & 936 \\
\hline 1204.87 & 9 & 1905 & 5924 & 2052 & 971 \\
\hline 1220.8 & 11 & 8980 & 5076 & 2525 & 1491 \\
\hline 1228.82 & 22 & 22090 & 5525 & 4837 & 2646 \\
\hline 1246.86 & 10 & 22092 & 5380 & 2197 & 1197 \\
\hline 1261.91 & 9 & 1482 & 5930 & 1965 & 984 \\
\hline 1308.82 & 9 & 3270 & 5412 & 1903 & 1159 \\
\hline 1332.87 & 25 & 17087 & 6426 & 5407 & 2834 \\
\hline 1340 & 105 & 16599 & 6165 & 22729 & 12255 \\
\hline 1341.99 & 24 & 11084 & 6238 & 5226 & 2747 \\
\hline 1348.04 & 83 & 46126 & 5795 & 17954 & 10688 \\
\hline 1349.03 & 47 & 1590 & 7131 & 10235 & 4465 \\
\hline 1350.03 & 10 & 1633 & 5647 & 2187 & 1329 \\
\hline 1352.02 & 8 & 942 & 6317 & 1654 & 817 \\
\hline 1361.99 & 42 & 11227 & 6764 & 9114 & 4484 \\
\hline 1364 & 18 & 7936 & 5573 & 3984 & 2521 \\
\hline 1367.06 & 18 & 5128 & 5873 & 3880 & 2258 \\
\hline 1374.89 & 8 & 4159 & 5619 & 1788 & 1184 \\
\hline 1377.97 & 12 & 5187 & 6049 & 2577 & 1480 \\
\hline 1384.97 & 13 & 11013 & 5967 & 2774 & 1689 \\
\hline 1390.05 & 13 & 3273 & 5408 & 2695 & 1881 \\
\hline 1413.98 & 10 & 2021 & 4459 & 2166 & 1920 \\
\hline 1424.09 & 22 & 6616 & 5893 & 4662 & 3052 \\
\hline 1429.02 & 468 & 18475 & 4920 & 97919 & 80929 \\
\hline 1431.04 & 195 & 40367 & 5349 & 40704 & 28829 \\
\hline 1451 & 12 & 4913 & 9025 & 2550 & 1094 \\
\hline 1451.99 & 13 & 12437 & 6124 & 2646 & 1715 \\
\hline 1600.98 & 25 & 45691 & 6412 & 4427 & 3360 \\
\hline 1628.19 & 9 & 2842 & 5269 & 1623 & 1612 \\
\hline 1640.21 & 18 & 19783 & 3174 & 3010 & 4668 \\
\hline 1645.19 & 11 & 8962 & 7649 & 1809 & 1220 \\
\hline 1659.18 & 17 & 27549 & 6628 & 2886 & 2233 \\
\hline 1676.21 & 399 & 41994 & 6230 & 65671 & 56140 \\
\hline 1678.19 & 103 & 27361 & 6089 & 16927 & 14042 \\
\hline 1692.21 & 246 & 37279 & 6210 & 39900 & 34831 \\
\hline 1694.21 & 66 & 30057 & 6180 & 10690 & 8991 \\
\hline 1698.17 & 12 & 6840 & 6132 & 1987 & 1790 \\
\hline 1706.2 & 21 & 3921 & 6865 & 3333 & 2598 \\
\hline 1708.22 & 41 & 27289 & 6246 & 6499 & 5656 \\
\hline 1724.21 & 15 & 16229 & 6713 & 2338 & 1915 \\
\hline 1736.24 & 11 & 2768 & 5955 & 1753 & 1731 \\
\hline
\end{tabular}




$\begin{array}{llllll}1739.24 & 14 & 11217 & 4324 & 2202 & 3012 \\ 1754.32 & 379 & 45855 & 5130 & 58977 & 69274 \\ 1756.33 & 139 & 27603 & 5382 & 21537 & 21172 \\ 1776.29 & 26 & 13286 & 6673 & 4032 & 3479 \\ 1804.34 & 11 & 3224 & 4682 & 1675 & 2208 \\ 1821.31 & 11 & 16381 & 5831 & 1626 & 1808 \\ 2551.9 & 57 & 154556 & 6503 & 2731 & 4119 \\ 2750.96 & 53 & 7723 & 4980 & 2015 & 3972 \\ 2792.98 & 212 & 274893 & 5398 & 7394 & 15480 \\ 3243.28 & 16 & & 7944 & 1003 & 579 \\ 3606.56 & 8 & & 7344 & 395 & 251 \\ 3738.33 & 1 & & 14461 & 48.4 & 18.8 \\ 3767.42 & 1 & & 10545 & 56.6 & 19.5 \\ 3777.78 & 4 & & 9229 & 195 & 119 \\ 3805.63 & 1 & & 12460 & 48.7 & 15.2\end{array}$

Abbreviation: $\mathrm{m} / \mathrm{z}=$ molecular ion $/$ charge; $\mathrm{S} / \mathrm{N}=$ signal $/$ noise; Quality Fac. = quality factor;

Res. $=$ resolution; Intens. $=$ intensity 


\section{Tryptic Digestion Pattern of Native and Modified Lysozymes}

$\mathrm{K} \sqrt{\mathrm{V}}$ F G $\mathrm{R} \sqrt{\mathrm{C}}$ E L A A A M K $\sqrt{\mathrm{R}} \sqrt{\mathrm{H}}$ G L D N Y R $\sqrt{\mathrm{G}}$ Y S L G N W V C A A $\mathrm{K} \leftrightharpoons$

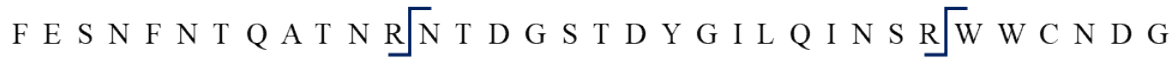

$\mathrm{R} \sqrt{\mathrm{T}}$ P G S R $\sqrt{\mathrm{N}}$ L C N I P C S A L L S S D I T A S V N C A $\mathrm{K} \sqrt{\mathrm{K}} \sqrt{\mathrm{I}} \mathrm{V}$ S D G

N G M N A W V A W $\mathrm{R} \sqrt{\mathrm{N}} \mathrm{R} \sqrt{\mathrm{C}} \mathrm{K} \sqrt{\mathrm{G}} \mathrm{T}$ D V Q A W I R $\sqrt{\mathrm{G}} \mathrm{C} \quad \mathrm{R} \sqrt{\mathrm{L}}$

Figure S21. Summary of the peptide bond cleavages as a result of trypsin digestion on lysozyme. Red and blue brackets correspond to the lysine and arginine cleavage sites, respectively.

K V F G R C E L A A A M K R $\sqrt{\mathrm{H}}$ G L D N Y R $\sqrt{\mathrm{G}}$ Y S L G N W V C A A K F E S N F N T Q A T N R $\sqrt{\mathrm{N}}$ T D G S T D Y G I L Q I N S R W W C N D G R T P G S R N L C N I P C S A L L S S D I T A S V N C A K K I V S D G N G M N A W V A W R $\sqrt{\mathrm{N}} \mathrm{R} / \mathrm{C}$ K G T D V Q A W I R G C R $\sqrt{\mathrm{L}}$

Figure S22. Summary of the trypsin digestion on lysozyme after glycoconjugation. Brackets refer to the cleavage sites. 


\section{Assay of Lysozyme Lytic Activity}

The lytic activity of lysozyme was determined according to the turbidometric method by using $E$. coli cells. Bacterial cells were harvested (7000 rpm for $10 \mathrm{~min}$.$) and re-suspended in Tris-Cl$ buffer $(\mathrm{pH} 7.5)$ at the $\mathrm{OD}_{600}$ of 0.8 . Lysozyme and modified lysozyme solution were added to the bacterial cell at the concentration of $60 \mu \mathrm{g} \mathrm{mL}-1$. Change in the OD was monitored at $37^{\circ} \mathrm{C}$ and recorded using a spectrophotometer up to 6 hours.

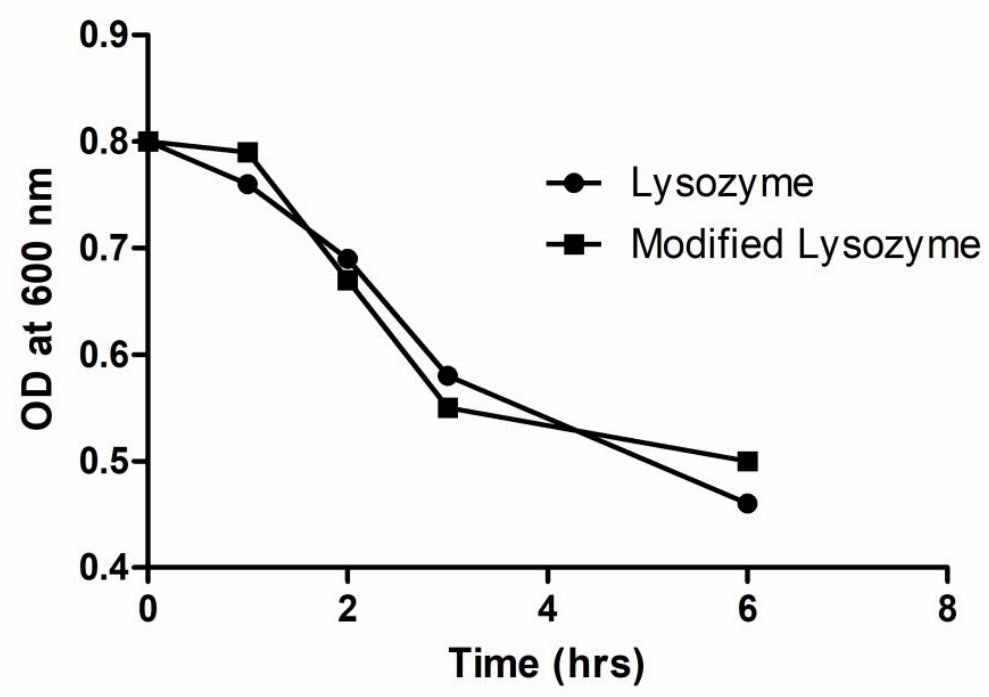

Figure S23. Plot of the lytic activity of native and modified lysozymes on E. coli.

\section{Reference}

1. Sambrook, J.; Fritsch, E. F.; Maniatis, T. (2001) Molecular Cloning: A Laboratory Manual, Cold Spring Harbor Laboratory Press. 